Universidad de Lima

Facultad de Comunicación

Carrera de Comunicación

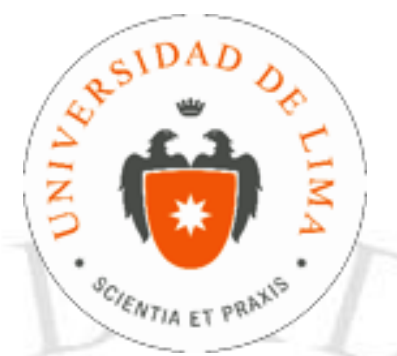

\title{
Full Tenis Perú
}

Trabajo de Suficiencia Profesional para optar el Título Profesional de Licenciado en Comunicación

\section{Milena Alessandra Federici Aguirre Código: 20102361 \\ Lucia Michelle Thais De Asin Garzon \\ Código: 20110365}

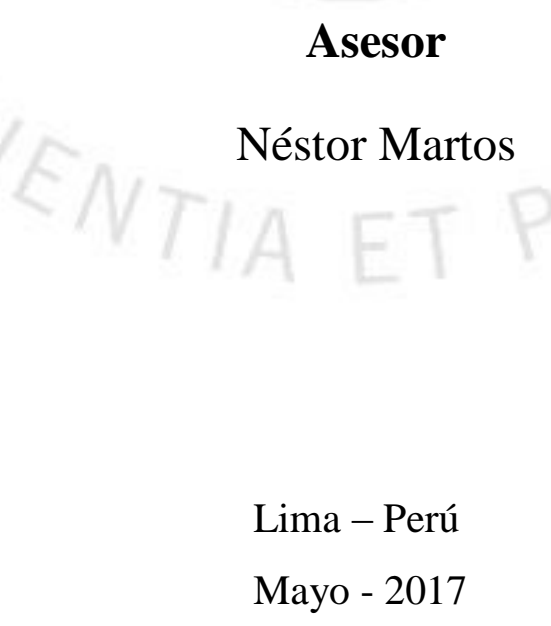




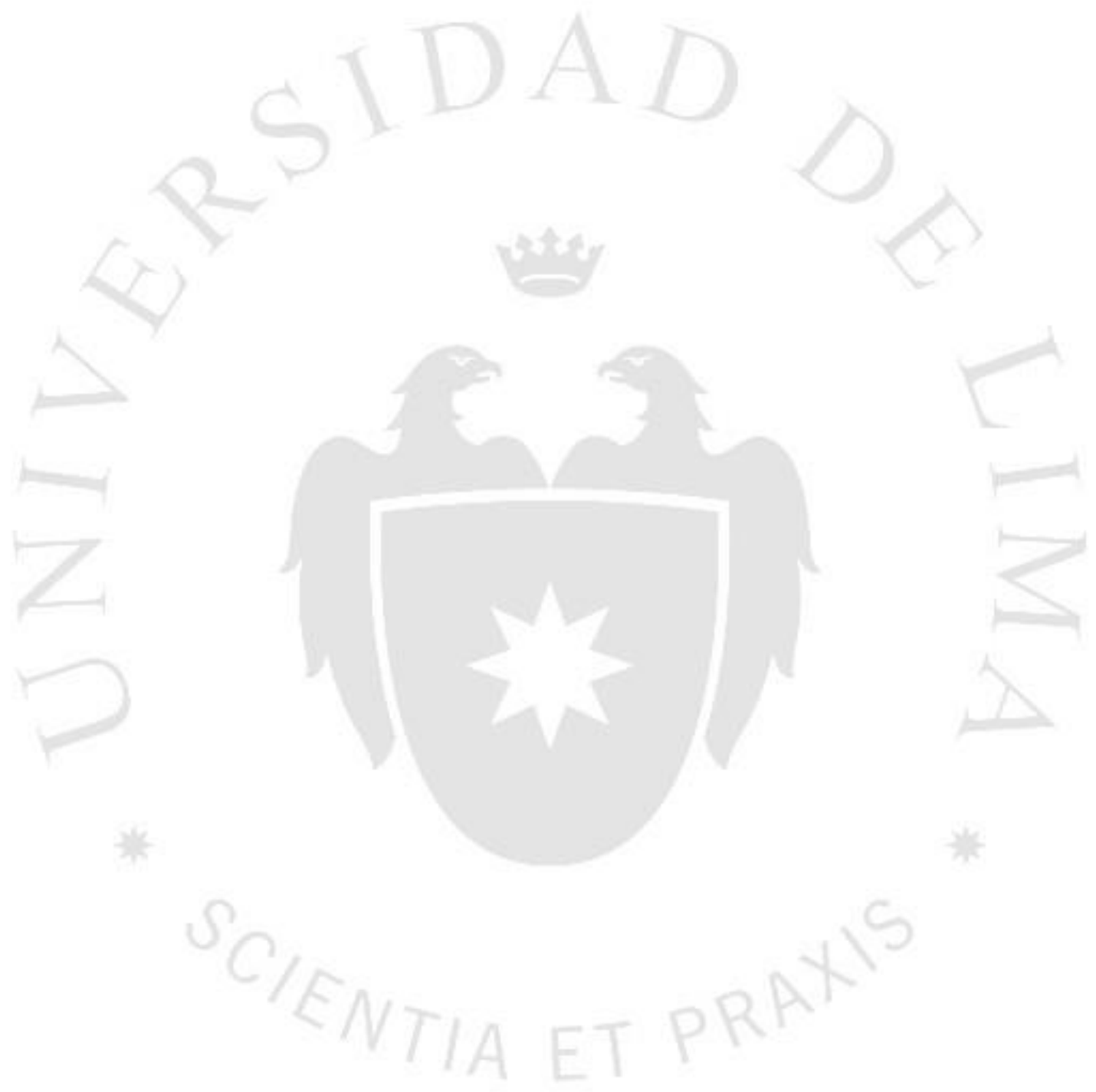




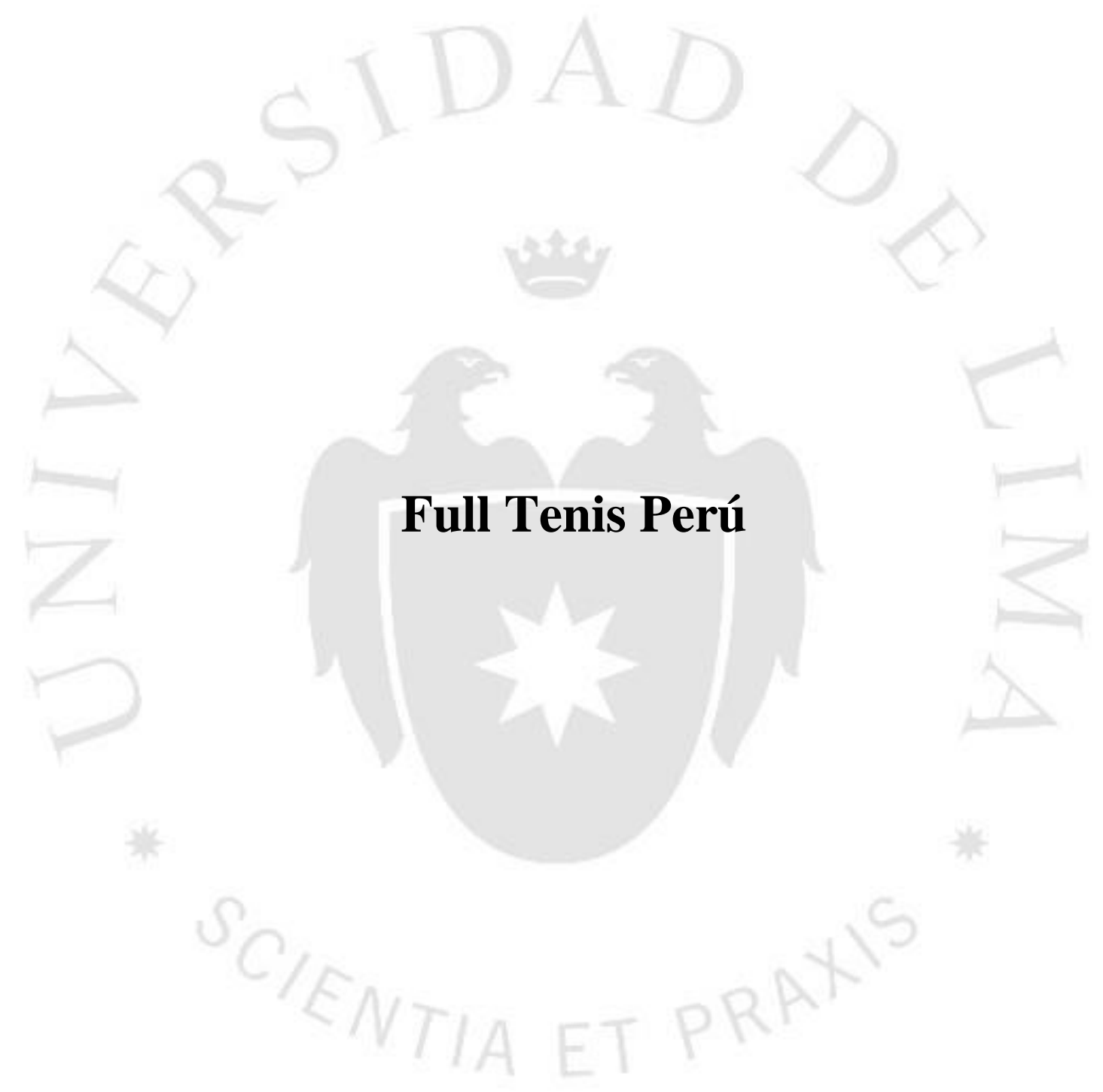




\section{TABLA DE CONTENIDO}

I. DIRECCIÓN ELECTRÓNICA DEL TRABAJO ............................

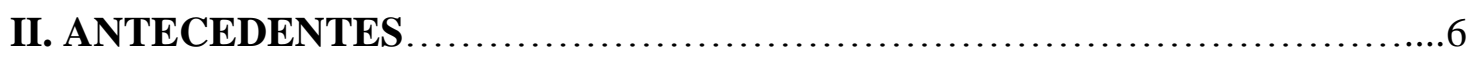

2.1 Páginas referenciales.............................................9

2.1.1 Tenis al máximo................................................ 9

2.1.2 Federación Deportiva Peruana de Tenis...............................11

2.1.3 International Tennis Federation (ITF) .............................. 13

2.1.4 Women's Tennis Association (WTA) ................................14

2.1.5 La Web del Tenis............................................... 15

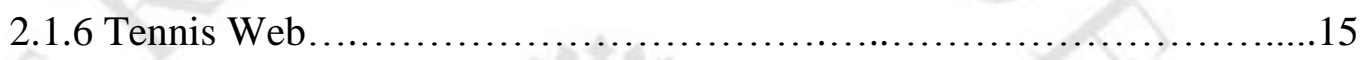

2.1.7 Tennis Senior- La web de tenis para veteranos..........................16

2.1.8 Tennis One................................................... 17

2.1.9 We are Tennis................................................ 17

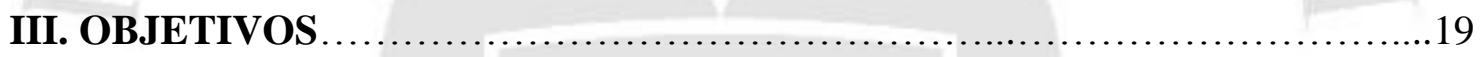

IV. ACCIONES SUSTENTADAS ..................................... 20

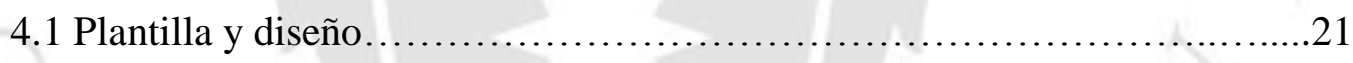

4.2 Logotipo.........................................................26

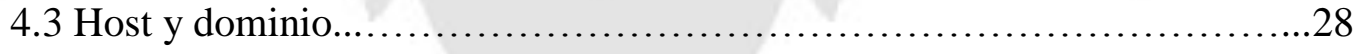

4.4 Contenido..........................................................28

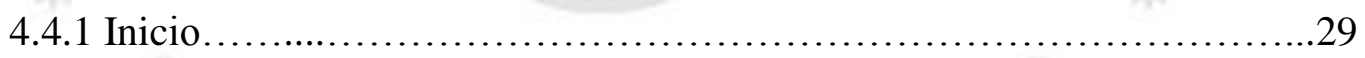

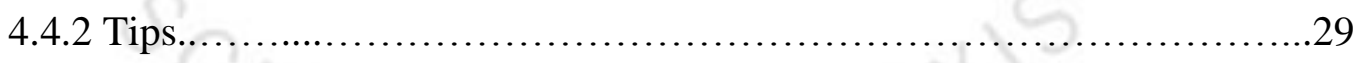

4.4.3 Tenistas peruanos............................................29

4.4.4 Academias.................................................... 30

4.4.5 Torneos...........................................................

4.4.6 Videos........................................................... 30

4.4.7 Contacto..................................................................

V. LOGROS Y RESULTADOS ............................................ 33

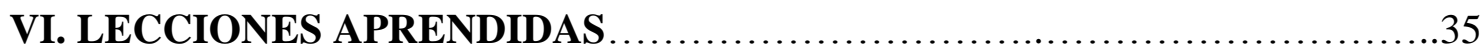


REFERENCIAS.

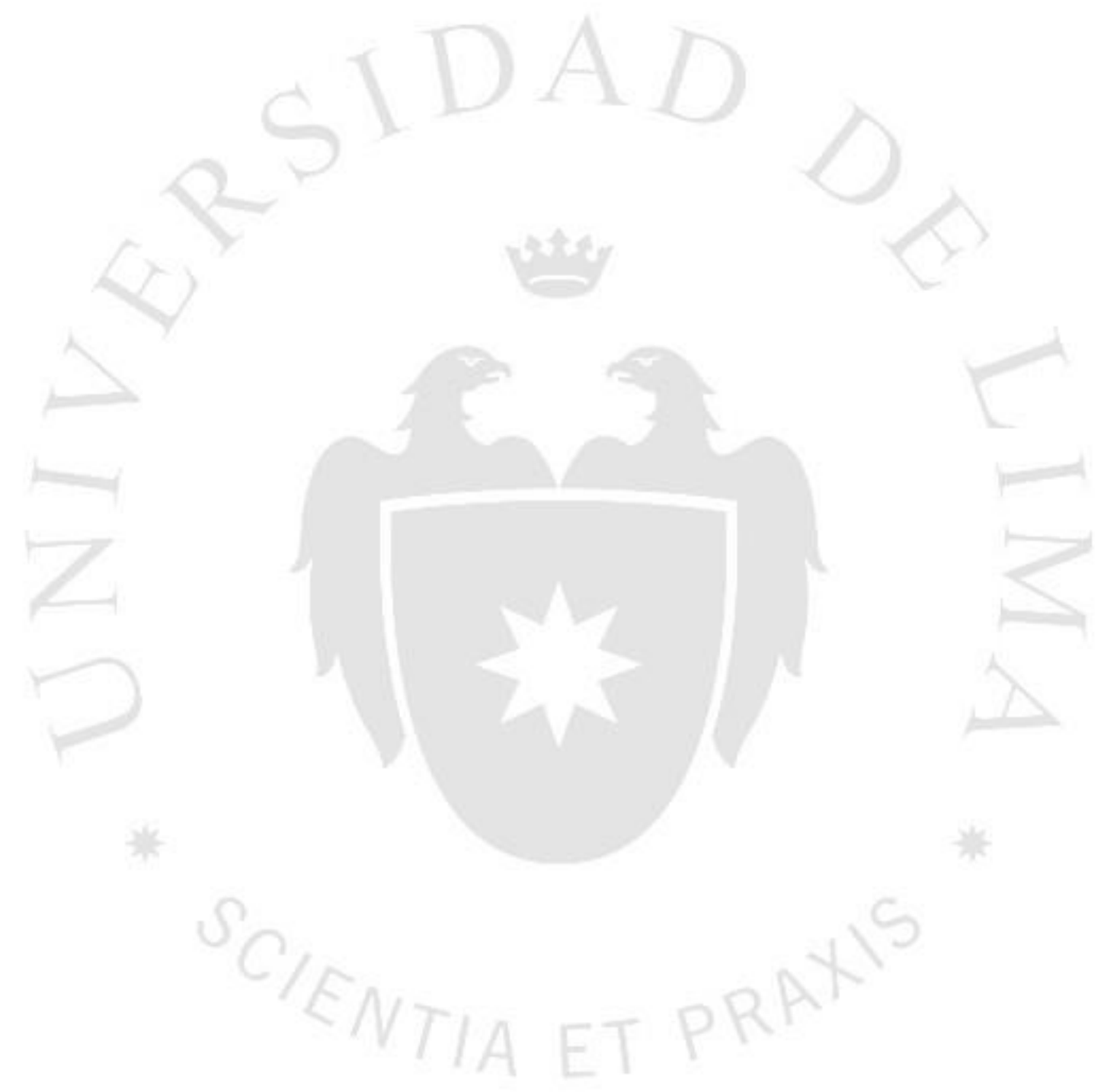




\section{DIRECCIÓN ELECTRÓNICA DEL TRABAJO}

www.fulltenisperu.com 


\section{ANTECEDENTES}

Full Tenis Perú nace en la Universidad de Lima en el curso de Proyecto de Especialidad el cual les permite a los alumnos llevar a cabo algún proyecto que tengan en mente, además de asesoramiento en el proceso a realizar. Nos dimos cuenta que la situación del tenis necesitaba apoyo. La idea nace con el propósito de crear una web integral ya que existía la carencia de una plataforma que esté al alcance de todos y sea completa; que incluya contenido tanto de tenis nacional como internacional, que brinde todo tipo de consejos relacionados a este deporte, información sobre academias nacionales y, sobre todo, que reconozca a los tenistas más destacados para así brindarles apoyo, darles valor y de cierta manera promover este deporte.

Inicialmente, cada una tenía un proyecto que quería realizar independientemente. Sin embargo, al llegar juntas al curso de Proyecto de Especialidad, comparamos los dos proyectos y nos dimos cuenta que podíamos unirnos y realizar algo más grande, completo y de contenido propio y original. Entonces, para desarrollar como se quería esta web de gran escala, se consultó con algunos profesores quienes nos aconsejaron qué si realmente se deseaba que el proyecto sea un éxito, se debía trabajar de manera conjunta y con total compromiso.

Por tanto, creemos que esta web nace en el momento oportuno ya que, en la actualidad, muchos tenistas peruanos han conseguido participaciones en los cuatro campeonatos de tenis más importantes del mundo en la categoría Junior, los llamados "Grand Slams" junior (Us Open, Wimbledon, Australian Open, Roland Garros). Nicolás Álvarez y Juan José Rosas han representado al Perú en las olimpiadas de China: "The 2nd Summer Olympic Games - Najin 2014". Además, el equipo de la selección peruana de tenis de la categoría junior, tanto de mujeres como hombres, han logrado clasificar al mundial realizado en República Checa en 2014 y también clasificaron al mundial de 2016 llevado a cabo en Budapest, Hungría, en el cual solo clasifican 16 países de todo el mundo.

Sin embargo, el tenis peruano no cuenta con mucho apoyo ni promoción por ninguna entidad $u$ organización peruana. Las clasificaciones recién mencionadas demuestran que definitivamente hay talento y los chicos tienen la oportunidad de viajar a estos torneos siempre y cuando representen al equipo peruano, ya que son financiados por la Federación y algunas entidades. Sin embargo, para que un tenista destaque a nivel mundial, no basta con participar únicamente de estos torneos (por equipos), sino, tienen que sumar puntos individualmente para escalar en el ranking y ser reconocidos internacionalmente. Para ello, tienen que viajar a todos los torneos posibles que se 
realizan alrededor del mundo y es ahí donde ganan los puntos que son determinantes para subir de puesto en el ranking internacional, teniendo como resultado que puedan clasificar y participar de los campeonatos más importantes del tenis mundial. En este punto es donde yace el problema mencionado sobre la falta de apoyo ya que muchos jugadores no pueden ganar estos puntos individuales debido a que se quedan sin viajar ni participar de los torneos por problemas económicos.

Si uno se pregunta ¿por qué no hay ningún tenista peruano dentro del top 100 del ranking mundial? o ¿por qué en otros países del mundo el nivel tenístico es mucho más alto que en nuestro país? La respuesta no es que los peruanos sean inferiores a los demás, sino que en otras naciones las federaciones apoyan a sus jugadores brindándoles tanto ayuda económica como buscándoles buenos entrenadores. En cambio, en el Perú no ocurre eso, por el contrario, existe una escasez de entrenadores de calidad que estén al mismo nivel de los entrenadores internacionales, y los pocos que hay son muy costosos, lo que dificulta que el tenista pueda explotar todo su potencial por la falta de horas de entrenamiento que no se pueden cubrir por un tema económico. Otro problema surge cuando los pocos tenistas que pueden financiar su entrenamiento en el Perú tienen que viajar. Esto se debe a que para tener un buen desempeño es necesario viajar con tu equipo de entrenadores, pero, así como deben asumir los costos propios del viaje, también deben asumir los de los entrenadores, tanto de pasajes como de estadía, alimentación, etc. Y eso ya es un gasto sumamente elevado. Por lo tanto, esto crea desmotivación en el mismo jugador que empieza a pensar si debe seguir con el deporte o no. Hay varios casos de tenistas que pese a ser los mejores del Perú, abandonaron el tenis profesional y la competición y se volvieron profesores de este deporte o cambiaron de rubro en su carrera.

Por ello, consideramos importante la creación de Full Tenis Perú para reflejar el valor que se merece este deporte en el país y así crear conciencia en las autoridades influyentes de este deporte sobre la falta de apoyo y conseguir diferentes acciones que beneficien a estos talentosos chicos como: ayuda económica, auspicios, becas de estudios en universidades extranjeras, etc.

Otro aspecto que consideramos para crear este portal es la inexistencia de una web completa sobre tenis y con énfasis en el ámbito local.

Existen muchas páginas web sobre este deporte en todo el mundo, pero no hay alguna completa ni especializada en el tenis nacional. Además, las pocas webs locales son muy incompletas, ya que no brindan toda la información necesaria sobre el deporte, por 
lo tanto, muchas personas interesadas en ello, ya sean los mismos jugadores o los fanáticos limeños, viven más informados sobre el tenis de otras partes del mundo que de su propio país. Esto demuestra la falta de interés que se le da al tenis en el Perú, el cual es un deporte muy popular a nivel mundial. Por lo tanto, con esta propuesta buscamos revertir esa situación.

Hemos elegido este tema, ya que el tenis es un deporte muy conocido con una alta participación a nivel mundial por lo que es interesante poder brindarle al público que goza de él, información relevante, original y necesaria sobre el deporte. Además, el tenis es un deporte como muchos otros que representa no solo el saber jugar, sino, disciplina, vida saludable, orden, paciencia, aprender a controlar las situaciones bajo presión, control de la persona, buena actitud, comportamiento, etc. Por lo tanto, es un ejemplo muy bueno a seguir para las personas, ya que así adoptan las buenas actitudes de sus ídolos y los llevan a la práctica en su vida cotidiana. Además, científicamente está comprobado que el hacer deporte es bueno para la salud, por ello, es relevante impulsar la práctica del deporte, en este caso, el tenis.

Por otro lado, vivimos en la época de la era digital, es decir, todos vivimos conectados al internet ya sea a través de un celular, una computadora, una tablet, etc. Es una ventaja aprovechar esta situación para explotar la web, se estima que será fácil tener acogida y captar un buen número de personas.

Además, según el reconocido entrenador de tenis Tupi Venero, la creación de una página web enfocada únicamente en el tenis limeño va a lograr no solo brindar información relevante, sino fomentar de manera más importante este deporte y contribuir a que las entidades encargadas, como la Federación Peruana de Tenis, tomen conciencia sobre lo importante que es apoyar de manera constante a nuestros jugadores para ayudarlos a crecer cada vez más como deportistas y que así puedan escalar en el ranking mundial.

Por último, muchos jóvenes y personas adultas disfrutan del tenis y muchos de ellos les gustaría aprender a jugarlo, pero al haber una escasez de información no saben dónde practicarlo o cómo hacerlo, es decir, qué raqueta usar, qué tamaño, qué peso es el adecuado, etc. Por ello, a través de esta web se busca incentivar a todas estas personas a practicar el tenis, ya que contarán con toda la información necesaria para su aprendizaje. También, los tenistas profesionales podrán gozar y sentirse más orgullosos de sus logros al tener una página dedicada a ellos donde se publicarán sus resultados 
y los de sus compañeros. Por todas las razones expuestas anteriormente apostamos en la web FullTenisPerú.

\section{PÁGINAS REFERENCIALES}

El mercado de páginas web sobre el tenis es muy simple y corriente. No existe alguna especializada en el tenis peruano y las pocas que hay no están completas, es decir, brindan información muy general y básica, más que nada, resultados de los competidores peruanos e internacionales. Hicimos una búsqueda de portales similares y nos dimos cuenta que en el Perú solo existían dos: la de la Federación Peruana de Tenis y Tenis al Máximo. En otros países sí existen más webs, sin embargo, estas no tienen contenido sobre el tenis peruano. Las páginas nacionales las consideramos incompletas y que no satisfacen las expectativas de los consumidores. Por ello, buscamos crear algo novedoso que logre llamar la atención del público. Queríamos obtener una web creativa, original, ordenada, visualmente agradable y sobre todo íntegra, diferente a las pocas ya existentes.

A continuación, veremos algunos ejemplos de páginas nacionales e internacionales.

\section{Tenis al Máximo}

\section{http://www.tenisalmaximo.com/index.html}

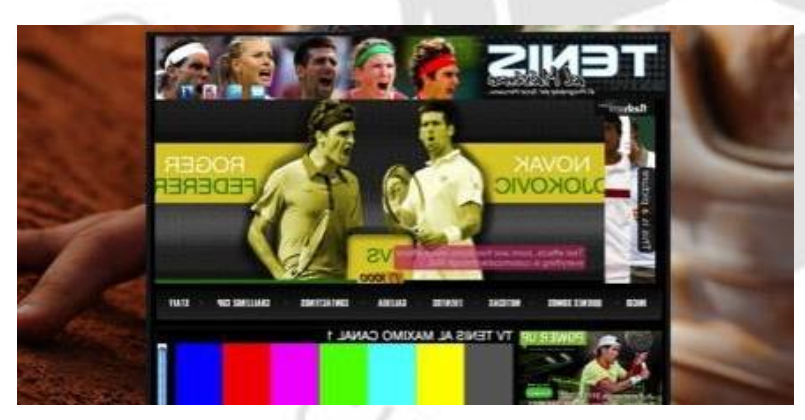

La página web Tenis al Máximo es peruana y publica información básica sobre el tenis nacional. Podemos ver que las ocho pestañas que tiene son de información básica y general (inicio, quienes somos, noticias, eventos, galería, contacto, Challenge cup y

staff) Además, la información no está completa ya que ingresando a varias pestañas aparece un vacío. Notamos que es muy pobre en el sentido de que un tenista aficionado o alguien que quiera aprender a jugar tenis no podrá averiguar mucho en esta página. Por lo tanto, hay una escasez de información. 


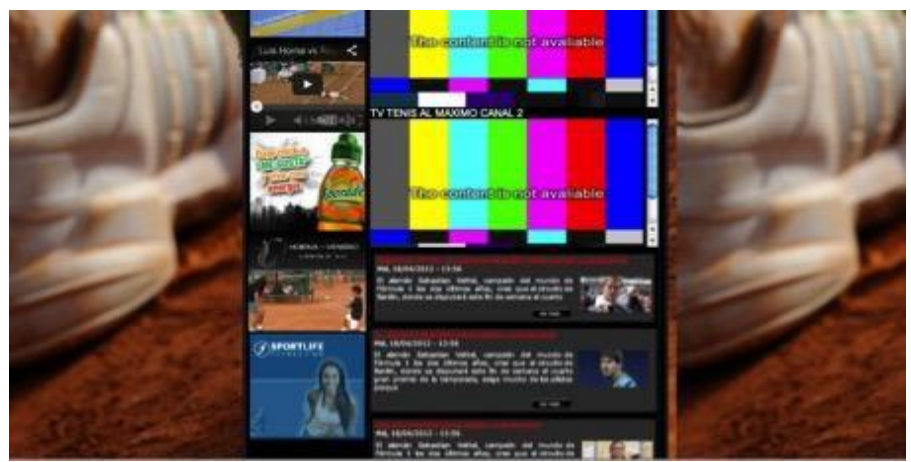

Asimismo, podemos visualizar que tienen dos pantallas para reproducir los campeonatos de tenis en vivo, pero la calidad de video es muy baja. También podemos notar que en la parte inferior existe una sección de texto en la cual publican los resultados de los partidos de tenis de jugadores de todos los países, es decir, no solo se centran en los peruanos. En la columna de la izquierda hacen una mención breve sobre una academia de tenis en Lima, además de colocar un poco de publicidad.

En 2016, la web se renovó y se le dio un carácter audiovisual, es decir, se basa en la transmisión y reproducción de partidos de tenis ya sea en vivo como en diferido.

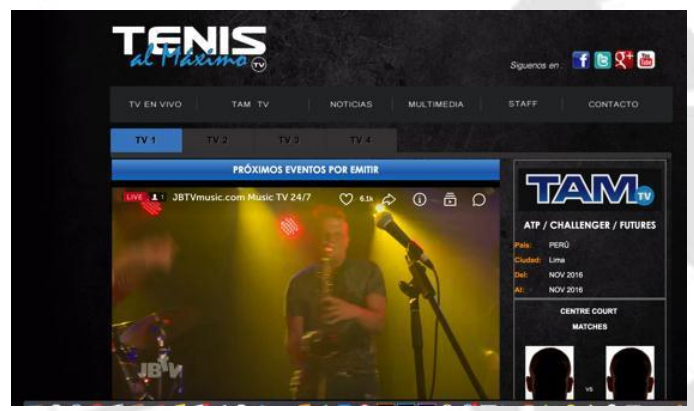

Tienen una sección donde publican noticias del tenis, sin embargo, priorizan las noticias internacionales más que las nacionales y además no hacen una distinción entre estas. Por lo tanto, no se enfocan en el tenis peruano a pesar de que es una web peruana.

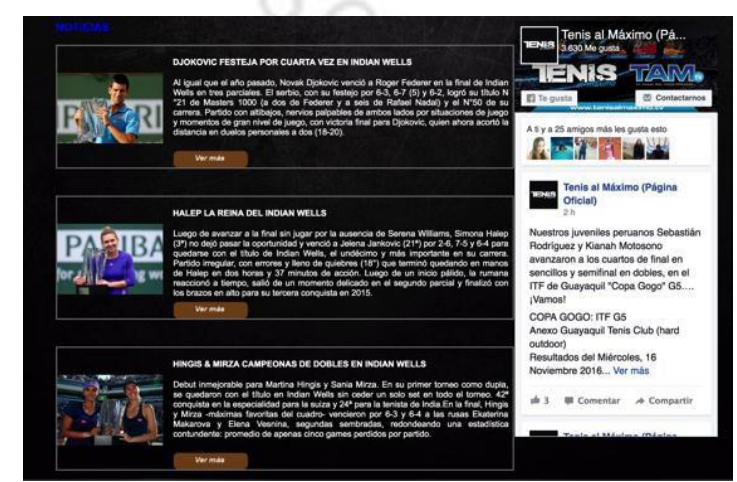

Adicionalmente notamos que no publican casi ningún otro tipo de contenido informativo sobre el tenis peruano. 


\section{Federación Deportiva Peruana de Tenis}

http://www.tenisperu.com.pe/tenis/index.php
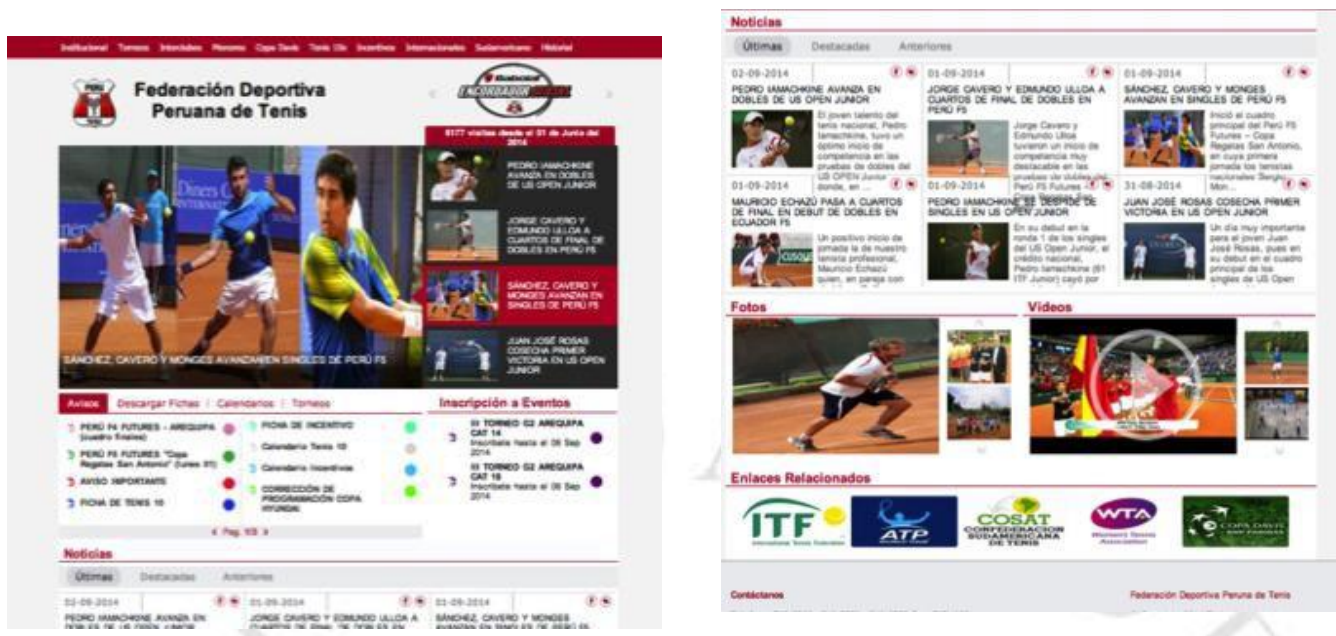

Esta es la página web oficial de la Federación Deportiva Peruana de Tenis. En esta página se exponen los rankings nacionales hasta la categoría de 18 años, las fechas de los torneos, noticias de último momento y un poco de historia sobre la Copa Davis.

Nuestra página web se diferencia de esta no solo en el formato y orden de la información, sino también en el diseño, color y sobre todo en el contenido de la página. El contenido de nuestra web será rico, original e incentivador, ya que no solo expondrá información sobre torneos y resultados, sino que también incentivará a los jóvenes a practicar este deporte al brindarles información sobre los lugares en los cuales pueden practicarlo, qué necesitan, qué raqueta usar, dónde conseguirlas, qué academias existen y se les brindará los mejores consejos dados por profesionales del deporte.

Además, podemos notar que hay una sección llamada noticias, en la cual presentan los resultados de los partidos ganados o perdidos por los jóvenes tenistas peruanos. Podemos notar que casi al final de la página, hay pocos videos colgados sobre algún evento importante en toda la historia del tenis, no necesariamente del momento. Además, hay una galería de fotos de diversos tenistas durante sus partidos Cuentan con un menú escaso de información. decir, no brinda consejos, tips, las principales reglas del tenis, etc. Además, se enfocan 
principalmente en los tenistas junior (menores de edad) publicando los campeonatos para ellos, pero olvidándose de los torneos profesionales para los jugadores mayores de 18 años que son los WTA Y ATP como los Future y Challengers. Además, el principal foco de la información brindada en la página se rige en fomentar a la misma Federación de Tenis Peruana más que al deporte en sí y a sus jugadores. Esto se notó porque la mayoría de contenido trata sobre la federación misma como, por ejemplo: su reglamento, sus leyes, su estatuto, etc. Si bien publican los resultados de los chicos que campeonan o participan de los torneos, no se les da un espacio especial para dar a conocer a cada uno de ellos y contar su historia, lo que motivaría a futuros jugadores.

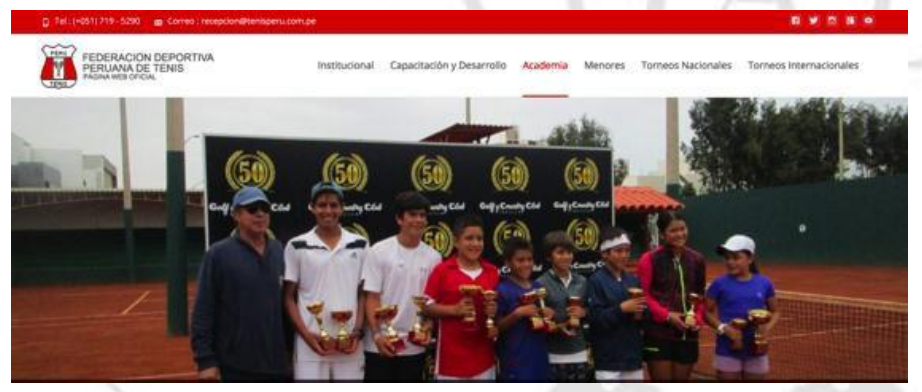

Además, como se muestra en la imagen, si se selecciona la categoría Academia, podemos ver que solo da información sobre la academia que tiene la federación y no sobre el resto que hay en Lima, lo cual desmotiva a los aficionados potenciales a aprender a jugar ya que no presenta una gama de opciones de lugares donde aprender que se ajuste al interesado.

En la categoría Torneos internacionales, la información es muy básica y genérica. Es decir, no publican el calendario de los campeonatos más importantes sino solo los resultados de estos y de una manera desordenada. Por lo tanto, los jugadores no pueden informarse a través de esta página sobre los torneos profesionales, muestran información incompleta sobre los torneos internacionales ya que solo colocan algunos a su gusto. También, hay ciertos lugares en la página donde se hace click para entrar y no muestra información, solo deja un mensaje que indica que la página está en mantenimiento, como se puede notar en esta imagen.

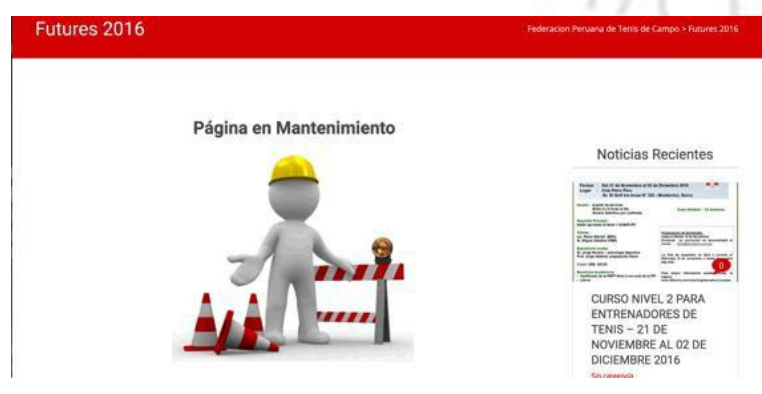


Esto se ha notado hace varios meses y sigue igual. Por lo tanto, se ve que no actualizan toda la página, dejan vacíos, lugares incompletos y eso genera un fastidio en los usuarios que no pueden encontrar todo lo que desean.

A continuación, presentaremos las páginas web internacionales:

\section{International Tennis Federation (ITF)}

\section{http://www.itftennis.com/home.aspx}

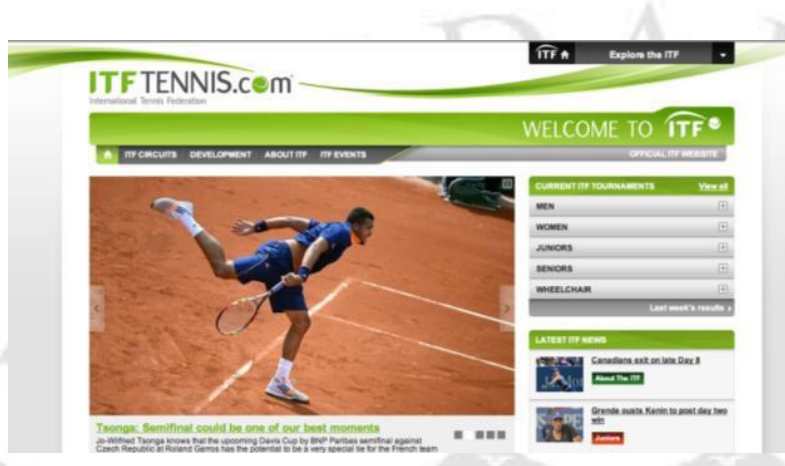

Esta web es la página oficial de la Federación del Tenis Internacional. En ella, podemos ver información tanto de damas y varones como de todas las categorías: menores, mayores, hasta los tenistas que juegan en una silla de ruedas a nivel internacional. Esta página está especializada en publicar los resultados de los campeonatos, los cuadros de juego y las fechas de futuros campeonatos.

Asimismo, existe una sección en la cual publican el ranking mundial de los jugadores y también te permite interactuar con la página ya que admite que escribas un tuit en la sección de Twitter que contiene.

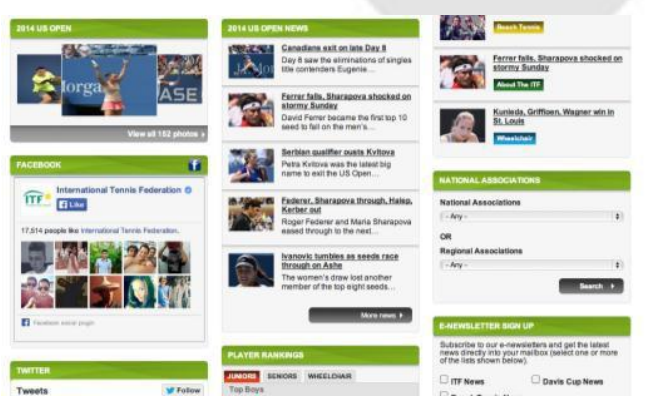




\section{Women's}

Tennis

Association

(WTA)

http://www.wtatennis.com/

Esta es la página oficial del tenis femenino a nivel mundial, es decir, está especializada

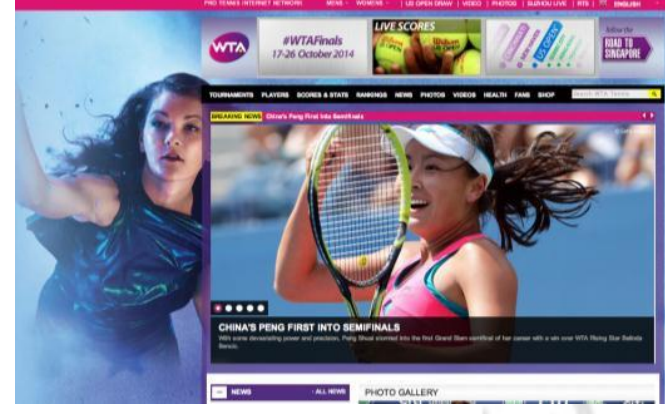
en presentar todas las noticias, resultados, eventos, fotos, etc. sobre este deporte en la rama femenina. Esta web es de carácter informativo ya que se exponen los resultados de los partidos y campeonatos más importantes del mundo, cuadros de juego, fotos sobre ellos, los rankings actualizados y últimas noticias.

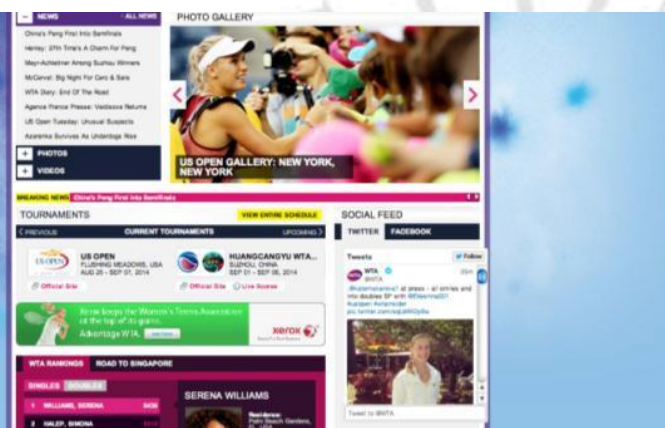

Asociación de Tenistas Profesionales (ATP)

http://es.atpworldtour.com/

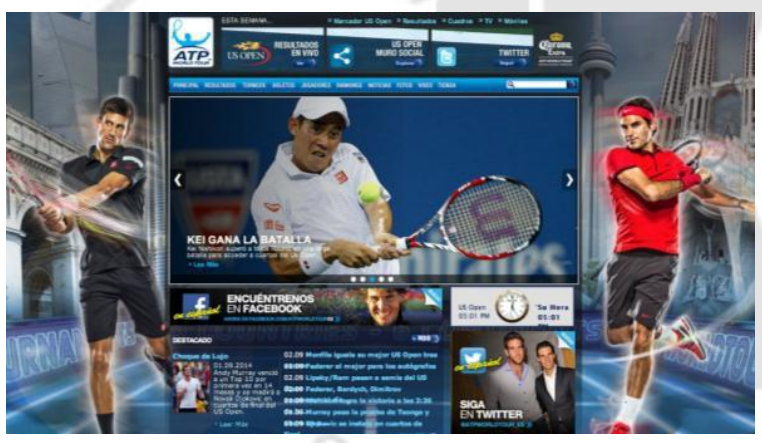

La página ATP (Asociación de Tenistas profesionales) es la web oficial de la asociación de tenistas profesionales, los competidores la usan para enterarse de las fechas de inscripciones de los campeonatos a nivel mundial y también para conocer los resultados y rankings del momento. Es

decir, esta página está especializada en el tenis mundial por lo que la información brindada es sobre los resultados de los mejores tenistas del mundo, tanto de damas como caballeros, así como de los campeonatos más importantes.

Asimismo, a través de esta página uno puede comprar boletos para los campeonatos más importantes del año, además existe la sección tienda, en la cual se venden productos del tenis oficial como polos con el logo de los torneos, toallas del diseño que utilizan los profesionales durante sus partidos, gorras, etc. 

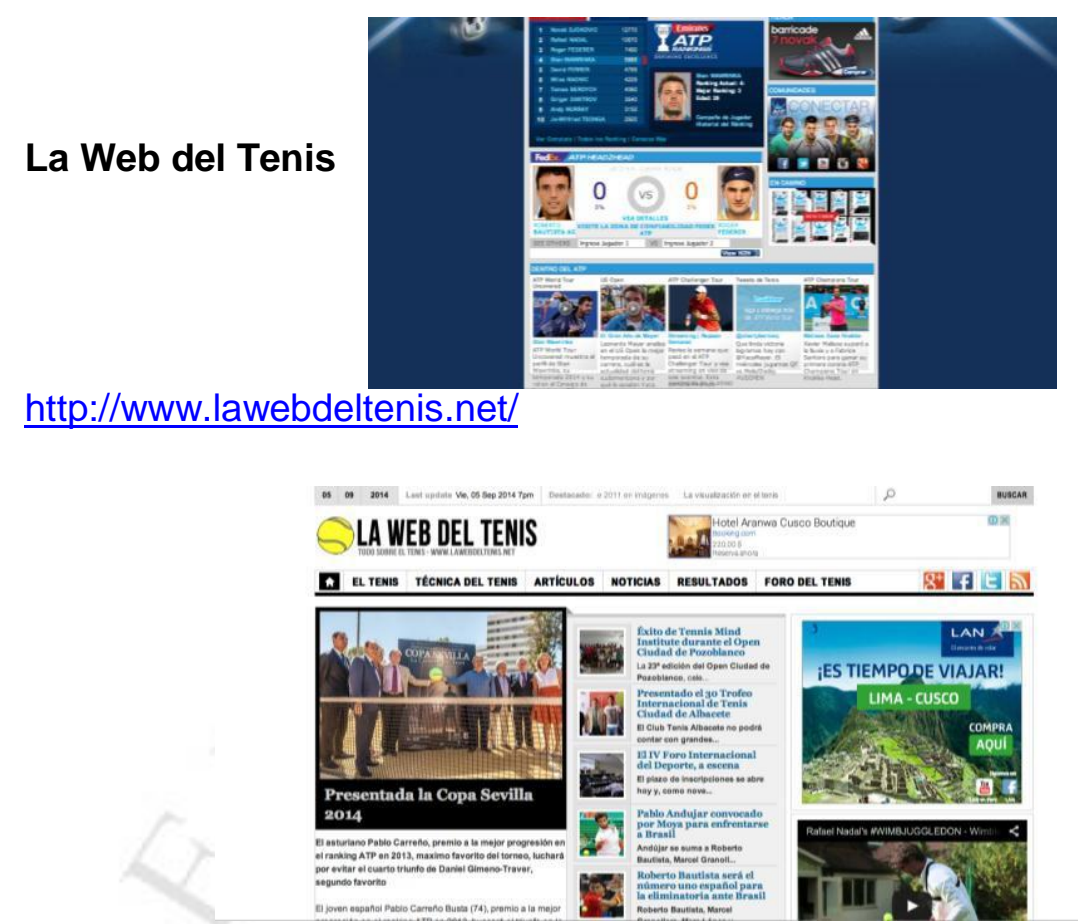

La web del tenis es una página española la cual es actualizada cada cierto tiempo. Las personas que ingresan a ella pueden saber cuándo fue la última fecha en que se actualizó, ya que en la parte superior se indica la última vez en que fue actualizada.

La página se enfoca principalmente en brindar información sobre el deporte en sí, es decir, brinda datos sobre las diferentes técnicas para jugar, todos los tipos de golpes que existen y en qué momento usarlos, etc. Además, publica diferentes artículos hechos por diferentes personalidades del tenis como por ejemplo: reconocidos entrenadores, profesionales, etc. También publica los resultados de los campeonatos de tenis más importantes.

Por último, cuenta con una sección llamada noticias en la cual publica los datos curiosos y de último momento sobre el tenis. No cuenta con muchas imágenes ni videos.

\section{TenisWeb}

http://www.tenisweb.com/

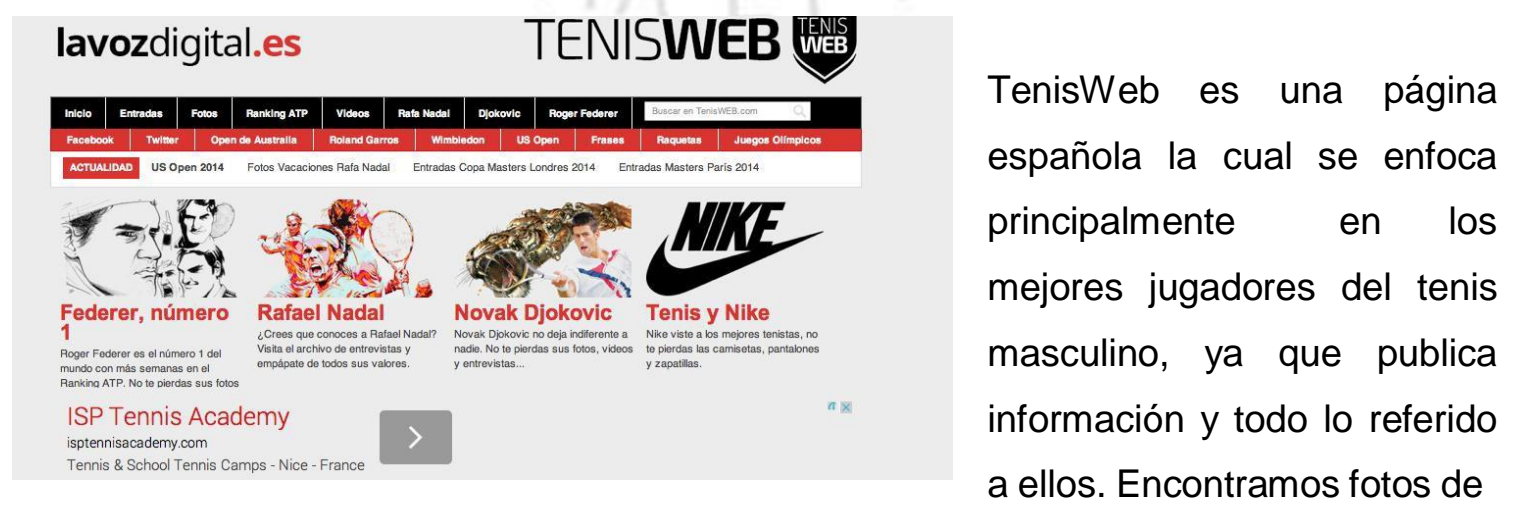


Nadal, Federer y Djokovic, junto con artículos sobre ellos y entrevistas que se les hicieron. Además de colgar fotos y videos, informa sobre la clasificación ATP, es decir, el ranking mundial, los juegos olímpicos, frases importantes dichas por los jugadores, etc.

Esta página se diferencia notablemente de las demás, ya que está orientada a brindar datos sobre los tres mejores tenistas del momento. Podemos encontrar varias fotos de ellos, videos, artículos, notas, entrevistas y la situación actual de cada jugador. Además, podemos notar que se hace una publicidad hacia la marca Nike ya que se le menciona únicamente con el título "Tenis y Nike".

Por último, podemos notar que la página no es fácil de leer ya que se encuentra de manera desordenada, los datos sueltos y el tamaño de las letras no es el adecuado.
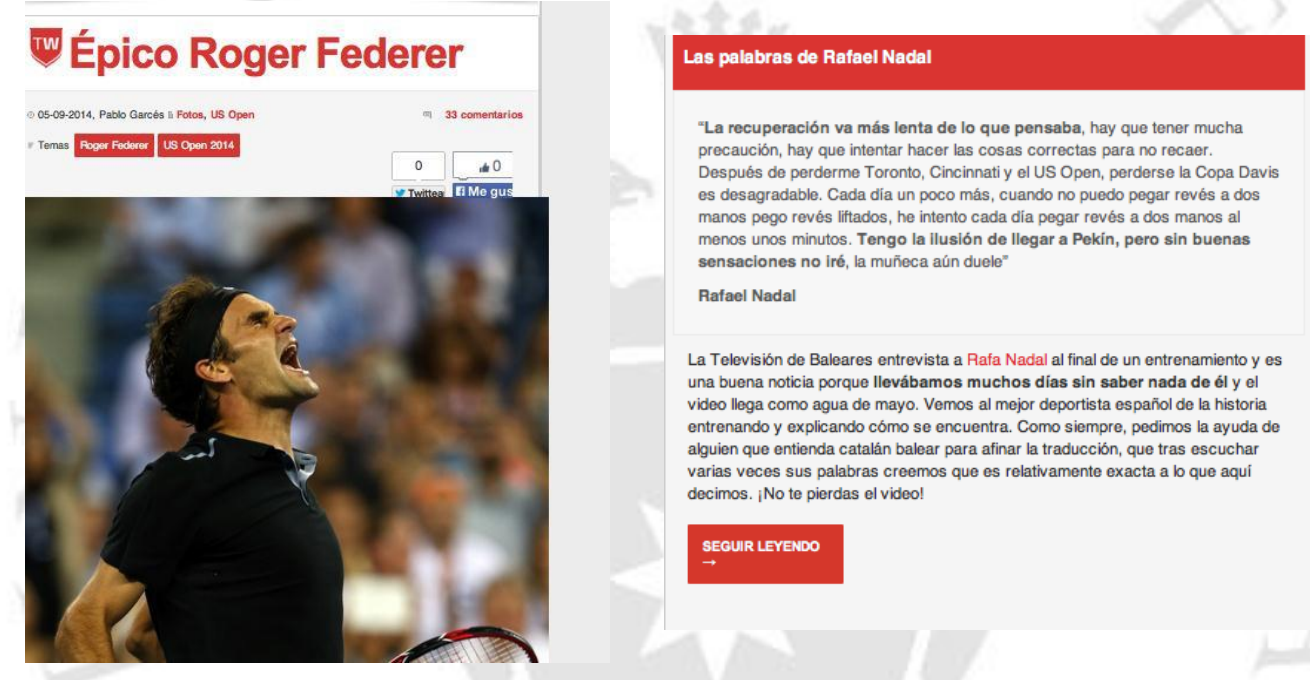

Tenis Senior - La web de tenis para veteranos

http://www.tenissenior.com/

Tenis Senior, como su nombre lo dice, es una web orientada al tenis adulto, es decir, al deporte para personas a partir de los 40 años en España, Barcelona. Su objetivo es alentar el deporte en las personas de esas edades informando sobre torneos en los

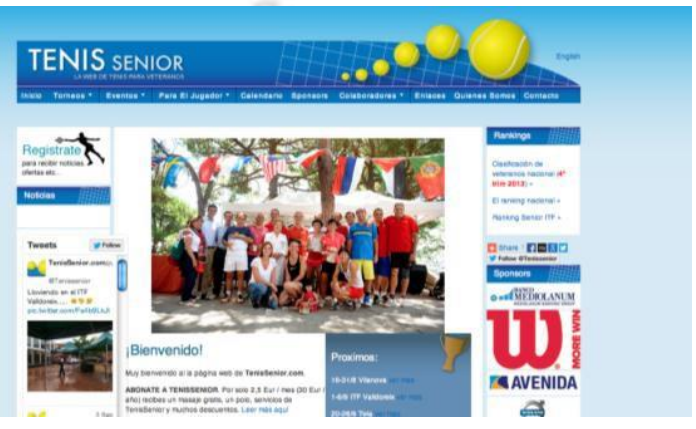
cuales ellos pueden participar, se les da la oportunidad de inscribirse en la misma página, además, informan sobre noticias y ofertas.

También se publican fotos de estos torneos y de los participantes para que se puedan ver en imágenes luego de haber finalizado el torneo. Además, hay una sección en la 
cual se brindan consejos sobre nutrición, preparación física, coaching mental, etc. Asimismo, luego de finalizados los campeonatos, se publica el ranking de los jugadores de la categoría Senior, así ellos saben en qué puesto se encuentran. La información se encuentra de una manera ordenada con buena legibilidad.

Por último, cuenta con una sección de Twitter en la cual uno con su cuenta puede escribir en la página y se publicará en esa sección inmediatamente. Puede ser una frase o incluso una foto.

\section{Tennis One}

http://www.tennisone.com/

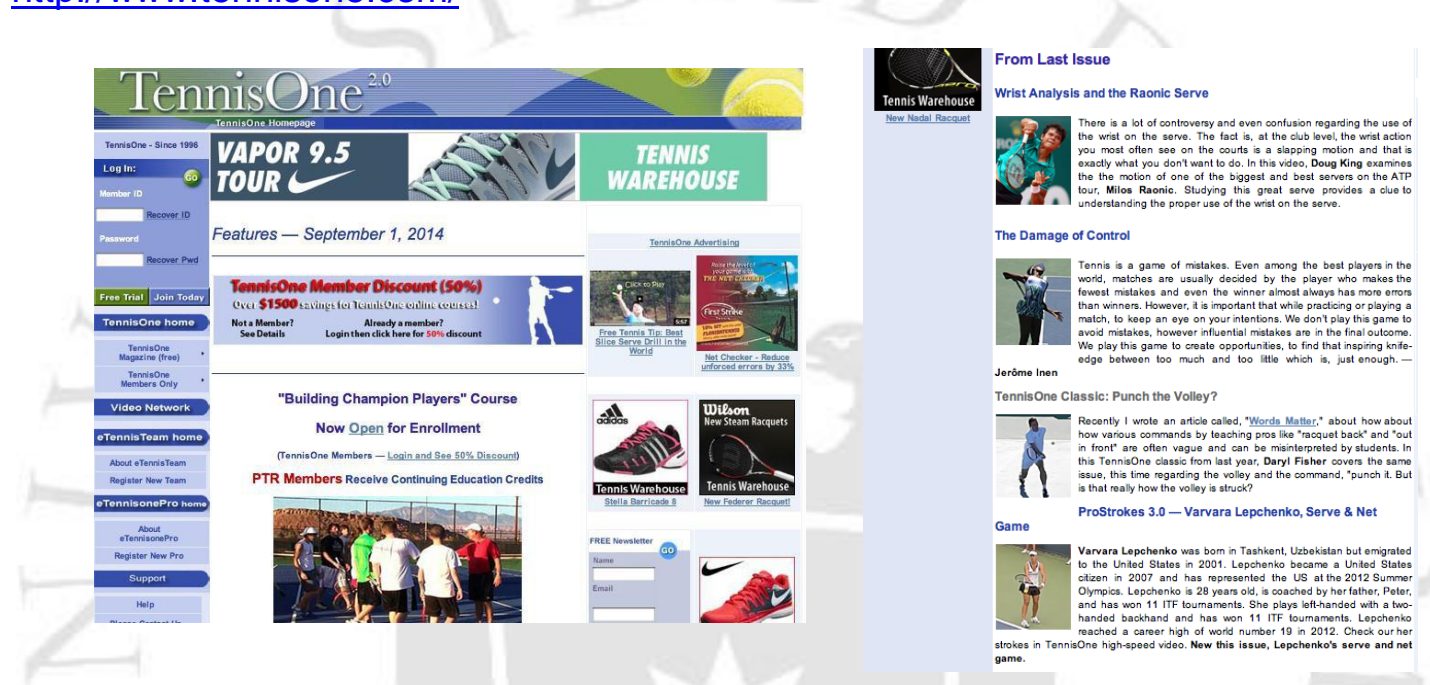

Tennis One es una página web de membresía, es decir, las personas interesadas en aprender a jugar el deporte y recibir información sobre clases, cursos, etc. ingresan a la página y se registran para ser miembros de ella.

Además, publican algunos artículos sobre el tenis, información sobre los rankings, pero primordialmente, está enfocada en reclutar a tenistas para volverlos clientes de la página y brindarles la información pertinente. Las personas que no son miembros de la página solo pueden acceder a información básica como resultados, rankings y algunos artículos, a diferencia de los miembros que reciben contenidos más elaborados. Para ser miembro de la página se tiene que pagar una mensualidad y de esa manera también poder participar en los cursos online de tenis.

\section{We are Tennis}

http://www.wearetennis.com/en UK/ 


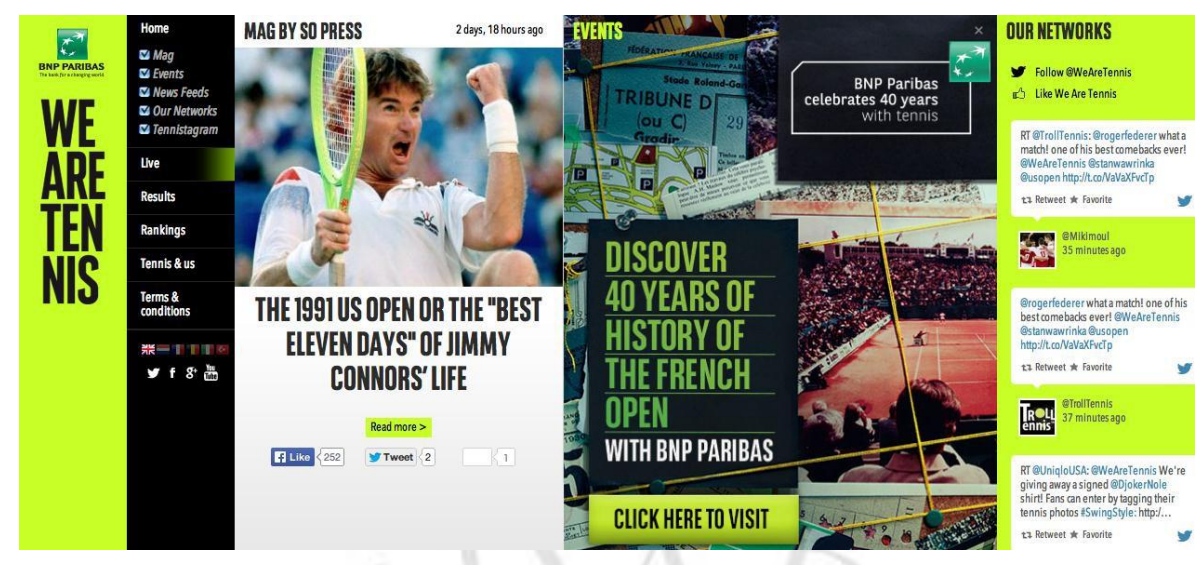

Esta página web es se diferencia del resto ya que se lee de forma diferente a las demás. Mientras que para leer el resto de webs uno tiene que subir y bajar el mouse, es decir, en manera vertical, esta funciona de manera horizontal (de derecha a izquierda y viceversa), lo cual rompe con el esquema común ya que las personas están acostumbradas a leer en el internet de manera vertical.

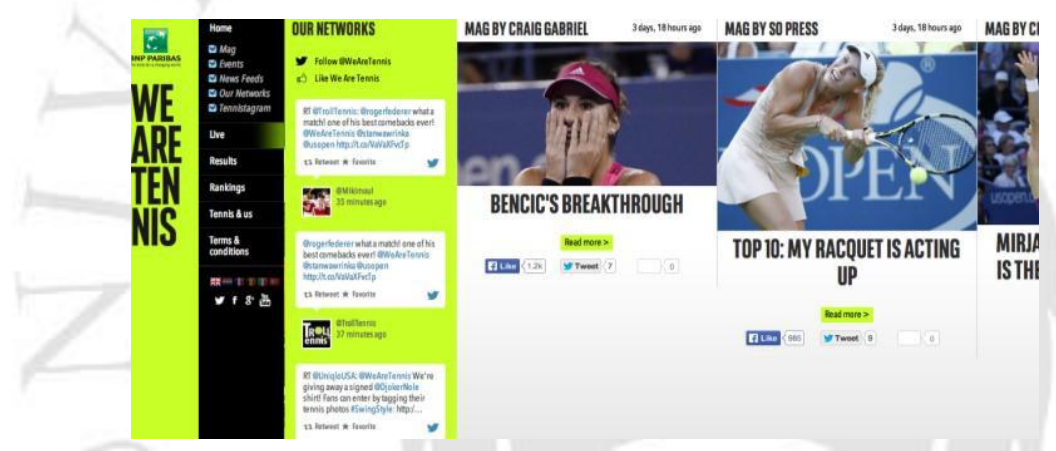

También, los títulos de las secciones que contiene están escritos en letras muy pequeñas por lo cual genera dificultad en la legibilidad, además de que ya se encuentra de una manera desordenada que uno no sabe por dónde empezar a leer.

La información que publica consiste principalmente en los resultados de los campeonatos y los rankings de los jugadores.

Finalmente, luego de revisar estas páginas web internacionales, pudimos notar que cada una tiene un enfoque diferente sobre el deporte, pero ninguna reúne toda la información sobre el tenis en una sola, ni contiene información sobre el tenis peruano. 


\section{OBJETIVOS}

El objetivo principal es la creación de una página web informativa que sea completa y esté enfocada en el tenis nacional sin dejar de lado lo más relevante del tenis internacional. Queremos llegar a todos los jóvenes y adultos, tanto tenistas como aficionados de este deporte. Hemos elegido este objetivo principal debido a la ausencia de una web peruana informativa y sobre todo completa.

- Ser la página de tenis peruana más vista por parte de los tenistas y aficionados a este deporte en el Perú.

- Lograr 200 vistas en la página web al mes

- Obtener 100 likes en el fanpage al mes.

- Generar tráfico en internet que sea mayor al de las páginas actuales de tenis en el Perú.

- Informar al público sobre el tenis nacional en diversos aspectos como resultados de campeonatos, rankings de los jugadores, eventos, torneos, academias, herramientas, tips, noticias, etc. Así, la página cuenta con toda la información relevante sobre este deporte para poder satisfacer las necesidades de su público que hasta ahora no cuentan con una página semejante.

- Crear conciencia en las autoridades como por ejemplo la Federación Peruana de Tenis y empresas privadas para que le brinden más apoyo a los tenistas peruanos.

- Incentivar este deporte en el país y que las personas que nunca se hayan animado a practicarlo, pero que son fanáticas de él, se animen a tomar clases o incluso metan a sus hijos en alguna academia de Lima. 


\section{ACCIONES SUSTENTADAS}

A continuación, se explicará paso a paso cómo se creó la página web "Full Tenis Perú" para que pueda estar online al servicio de todos los fanáticos del tenis, y puedan navegar y enterarse de las últimas noticias sobre este deporte a nivel nacional como internacional, próximos eventos, resultados, rankings, imágenes, videos, tips, entre otros.

Como primer paso, se realizó una búsqueda de páginas web peruanas e internacionales sobre el tenis para analizarlas y comparar las cualidades y desventajas que tienen y realizar un proyecto de calidad. Estas páginas ya fueron mencionadas previamente y detalladas tanto en contenido como en diseño.

Se eligió realizar este proyecto en una página web debido a que el carácter de este trabajo es informativo, por lo tanto, era la plataforma más adecuada para colgar todo el contenido que se consideró para organizarlo de una manera ordenada, legible y personalizada. Si se preguntan, por qué no se utilizó Facebook que es la plataforma más visitada por los usuarios digitales, la respuesta es muy simple. Facebook tiene una interfaz limitada que no se ajustaba a los requerimientos que nosotras necesitábamos para hacer la página fluida, de fácil lectura y organizada. Es decir, en Facebook se iba a perder el contenido mientras pase el tiempo, ya que su forma de publicación visualiza lo más actual en la parte superior, ocultando las publicaciones anteriores o dejándolas en la parte inferior de la página, de esa manera dificultando al usuario de encontrar de manera rápida y sencilla publicaciones del pasado. En cambio, en la página web, todo el contenido está a la mano del usuario gracias al menú principal que permite crear a gusto una página web, el cual se desglosa mostrando todos los títulos que contiene la página, logrando así una sencillez en la búsqueda de información que requiere el usuario, lo cual Facebook no lo permite. Asimismo, la página web nos permite organizar el contenido usando distintas categorías mediante el menú recientemente mencionado de una manera amigable y limpia para la lectura del usuario. En cuanto a Facebook, este no permite crear un menú que incluya las distintas categorías de información, es limitado y por ello nos dimos cuenta que con el transcurso del tiempo se iba a perder la información y se iba a visualizar de manera muy desordenada. La página niumedia.mx, creada por expertos en Marketing Digital de San Luis Potosí, México, hizo una comparación entre una página web y Facebook y concluyó lo siguiente: "Página 
Web: Puedes hacer que tu página web se vista de los colores de tu marca, crear formas únicas y llamativas de que el contenido luzca lo que quieres expresar, y puedes hacer estos cambios a tu propia discreción". En cuanto a "Facebook: Todas las páginas de Facebook se ven iguales, tal vez se puede poner tu logo y algo de información en la cabecera, pero si Facebook un día despierta con ganas de cambiarlo, lo hará y aun cuando no te guste". Esto confirma nuestra decisión de utilizar una página web como principal medio.

Además, en una página web nosotras podemos tener el control total del manejo en la plataforma, sin tener que ajustarnos a las condiciones de Facebook, lo cual nos da libertad para modificar a nuestro gusto todo el contenido, plantilla y sobre todo el diseño. Según un análisis que encontramos en internet por niumedia.mx nos indica que "Tú eres el dueño de tu página web, esto te da completo control sobre tu información y como se muestra". En cambio, para "Facebook: Tienes que acoplarte a los términos y condiciones del espacio que te prestan para que alojes tu contenido, el cual es constantemente revisado, si haces algo que ellos creen que no es bueno, pueden borrar tu cuenta”. (2014)

Sin embargo, a pesar de las limitaciones que tiene Facebook, reconocemos la importancia de utilizar esta red social ya que tiene una alta participación de los usuarios digitales, sobre todo de nuestro público objetivo, volviéndola la más popular y atractiva entre los usuarios. Por ello, decidimos complementar la página web con un fanpage las cuales están linkeadas para que los usuarios conozcan ambas páginas y puedan estar presentes en los lugares más frecuentados por el público objetivo. La información que incluye el fanpage ajustada a la estructura de Facebook será menor a la que existe en la página web, pero sin dejar de lado lo más importante como fotos, videos, noticias y consejos, que se adaptan a la personalidad de Facebook. Según el estudio del perfil del adulto joven de Lima Metropolitana de IPSOS 2011, dentro del perfil tecnológico, podemos observar que la mayoría de este grupo cuenta con algunos aparatos tecnológicos y suelen conectarse a internet varias veces por semana. Además, aproximadamente el $89 \%$ cuenta con un equipo celular y la mayoría de ellos tiene una cuenta activa en Facebook, más común en los NSE A con un $91 \%$ y B con un $90 \%$.

\section{Plantilla y diseño}

El primer paso fue determinar qué plantilla utilizar para la creación de nuestra página web. En el transcurso de la búsqueda, nos dimos cuenta que ninguna satisfacía lo que queríamos lograr y por ello decidimos crear una plantilla propia, original y personalizada. 
Para ello, se necesitaba conseguir a un experto en creación y programación de páginas web, para que creara la plantilla con el diseño que se deseaba y brinde asesoramiento según su punto de vista como experto. Iniciamos la búsqueda de este profesional a través de amistades, familiares, conocidos, colegas, etc. ya que queríamos a una persona de confianza y es así como se llegó a Koky Williams Delgado Martínez, experto en diseño y páginas web. Él ya había trabajado antes con un amigo quien nos lo recomendó. Se conversó con él, se le contó la idea del proyecto y notamos que efectivamente era la persona adecuada para trabajar en el proyecto.

Luego, se le indicó cómo queríamos que sea la página web en cuanto a diseño, paleta de colores, distribución de elementos, cantidad de categorías, el desglose, tipo y tamaño de letra, etc. Con toda esta información, Koky armó la plantilla web y después de unos ajustes, quedó como se esperaba.

Los colores que se utilizan en la página remiten al tenis como por ejemplo: amarillo, por la pelota de tenis, blanco, ya que este es conocido como El deporte blanco, además de que uno de los 4 campeonatos más importantes del mundo, Wimbledon, se juega obligatoriamente de color blanco. Por último, el color naranja que evoca a la arcilla, característico de las canchas de tenis. Por otro lado, tenemos los colores que remiten al Perú como blanco y rojo, por la bandera de la patria.

Se tratará de utilizar una buena combinación de estos colores mencionados para que la página se vea elegante y logre ser de carácter fino. "Muchos publicistas incluso indican que la asociación de los colores a una marca es tan fuerte, que una mala combinación puede llevar al fracaso. Hay que saber elegir los colores cuidadosamente, pues una visita decide en cuestión de segundos si se queda o no en la página web".

\section{http://es.jimdo.com/2012/11/13/5-reglas-sobre-el-color-el-\%C3\%A9xito-de-un- dise\%C3\%B10-web-profesional/}

La elegancia se verá reforzada con tonos negros ya que el negro es considerado un color que denota elegancia. Fiori Santa María, diseñadora y especialista en marketing, explica en su artículo sobre la teoría del color para diseñadores en la página Staffcreativa, http://www.staffcreativa.pe/blog/teoria-del-color-disenadores/, que el color negro: "es el más fuerte de los colores neutros. Es comúnmente asociado al poder, elegancia y formalidad. Es usado frecuentemente en diseños muy elegantes. En el diseño web el negro suele ser usado para las tipografías y otras partes funcionales debido a su neutralidad, puede lograr fácilmente una sensación de sofisticación." 
Distintos autores coinciden en el mismo hecho que el diseño a la hora de crear una página web es muy importante tanto como el contenido. El diseño de una página web va a determinar el éxito o fracaso de la misma. A continuación podremos apreciar las distintas opiniones de diversos autores especializados en páginas web.

El autor Cristian Graglia menciona en su artículo La importancia del diseño en los sitios web: "Si conseguimos esto: un sitio web con un diseño adecuado y una navegación correcta y sencilla, los visitantes tienden a permanecer más tiempo y volverán más a menudo" (2012). Con esto podemos notar que si queremos lograr captar gente que visite la página web constantemente y a futuro, es primordial y de suma importancia contar con un buen diseño.

Además, Graglia también afirma en su artículo que gracias a estudios científicos, está comprobado que: "El 75\% de los usuarios evalúan la credibilidad de un sitio basándose en el diseño web". (2012). Esto quiere decir que el diseño web no solo genera agrado visual sino también credibilidad en los consumidores, es decir, una persona confiará más en una página web con un mejor diseño que otra con posiblemente mejor contenido pero mal diseño Web.

Asimismo, Manuel Gil, director de BlueCaribu Colombia, indica en su artículo ¿Es realmente importante un buen diseño web? sobre un estudio realizado: "Como pueden ver, el diseño tiene un impacto significante en los visitantes de sitios web. No solo les afecta, sino como muestra este estudio, es el factor más influyente en la generación de confianza o desconfianza de un sitio." (2012)

También nos dice que: "Ios consumidores no hacen distinción entre un producto y su empaque. En lugar de ello, en la mente del consumidor, el producto es una combinación del empaque y el producto." (2012). Esto quiere decir que uno no puede separar el diseño del contenido, sino, estos dos se complementan y son de igual importancia para crear el producto final y esto determinará el éxito e impacto de la página web en su público.

Por ello, Gil afirma que: "Si estás a punto de construir un sitio web o estás considerando rediseñar uno ya existente, no es necesario que sea la página más bonita de toda la red, pero sí necesita lucir bien. Necesita transmitir calidad y profesionalismo, con una presentación organizada y armónica, buen uso de colores y bloques de texto fáciles de leer." (2012). Es muy importante que la elección de los colores a utilizar junto con el 
contenido de la página sea de manera armónica, ordenada y de buen agrado visual ya que eso es lo que transmite buena calidad.

Otro autor llamado Xavier Valdés afirma la misma teoría sobre el diseño de páginas web al mencionar en su artículo La importancia del diseño web que: "En resumen, puede afirmarse que el objetivo principal de esta fase de diseño es conseguir que el sitio web tenga un aspecto agradable, a la vez que transmite los valores de la marca en la forma adecuada y siguiendo la línea de comunicación corporativa requerida por el cliente". (2014).

Por otro lado, el tenis es un deporte que requiere disciplina, rapidez, soportar situaciones bajo presión, etc. Como menciona el profesor de tenis Sebastián Ortiz en su artículo La percepción visual en el tenis: "Según un estudio de la Escuela Politécnica Federal de Laussane (Suiza) los jugadores de tenis son más precisos que otros deportistas a la hora de detectar y reconocer objetos en movimiento o estimar su velocidad, lo que les permite tomar decisiones muy rápidas bajo presión".

Por último, Steve Jobs menciona en una de sus entrevistas: "Si eres un carpintero y estás haciendo un mueble, no vas a usar un pedazo de madera de contrachapado en la parte de atrás aún cuando sabes que estará frente a una pared y nadie la verá. Igual sabes que está ahí, pero usas una pieza hermosa de madera. Para poder dormir bien por las noches, la estética y la calidad tienen que ser llevadas a cabo en absolutamente todos los aspectos del producto". Esto nos dice que el diseño marca la calidad del producto final por lo que hay que tener mucho cuidado a la hora de crear el diseño de una página web si deseas que sea exitosa.

Esta frase fue encontrada en la siguiente página:

http://www.colbenson.es/colbensonlive/-/asset publisher/v4m6416yXo8t/content/laimportancia-del-diseno-en-los-sitios-web

Una vez que el diseño y la arquitectura de la página estaban perfectos, se empezó a enviarle el contenido como artículos, fotos, videos, noticias, etc. para que él las suba a la web. Se creó un grupo en Facebook con el programador en donde se enviaban todos los materiales que se debían subir a la web. Las fotos se enviaban en formato JPG ya editadas y si pesaban mucho, se comprimían en un ZIP. Luego, las notas periodísticas y todos los textos se creaban en un documento Word. Luego de ser revisadas varias veces, se le enviaban en este mismo formato al programador para que las publique. En cuanto a los videos, se le enviaba el enlace de Youtube para que el, con sus 
conocimientos, lo exponga en la web y no solo se vea un enlace, sino el video propio.

Durante la búsqueda de referencias de otras páginas web internacionales se analizó el diseño y los colores que utilizan y sus resultados de impacto visual. La página International Tennis Federation (ITF), http://www.itftennis.com/home.aspx, utiliza básicamente dos: el blanco y el verde, lo cual logra que la página sea de carácter legible y se vea ordenada. Además, podemos notar que hay más imágenes que texto y la información está colocada de una manera ordenada y fácil de utilizar. Luego, encontramos la página oficial de la asociación de tenis mundial de mujeres (WTA), http://www.wtatennis.com/, que utiliza colores como morado, rosado, celeste claro y blanco, los cuales son colores femeninos. Estos, más que remitir al tenis, nos dan una sensación de feminidad, lo cual es el carácter de la página web por lo que cumple con su objetivo. Además, al utilizar pocos colores, la página se ve elegante, fina, ordenada y legible.

Respecto a la Asociación de Tenistas Profesionales (ATP), http://es.atpworldtour.com/, los colores utilizados son pocos: azul, gris y negro, lo cual al ser combinables entre si, logran una página elegante, fina, ordenada, y de agrado visual.

En cuanto a La Web del Tenis, http://www.lawebdeltenis.net/, los colores predominantes son el blanco, negro y amarillo. Todo el fondo de la web es blanco y las letras están escritas en color negro, por lo tanto, hay buena legibilidad, pero no llama mucho la atención ya que al ser blanca y negra aburre un poco y no cautiva al público.

TenisWeb, http://www.tenisweb.com, utiliza rojo y negro como colores predominantes, los cuales crean un contraste muy fuerte que no te remite el deporte. Otra página, dedicada al tenis para veteranos: Tenis Senior, http://www.tenissenior.com/, utiliza principalmente el color azul y amarillo, los cuales remiten al tenis además de crear buen contraste, captando así la atención visual del público y logrando un agrado visual.

Por último, notamos que la página We are Tennis, http://www.wearetennis.com/en_UK/, tiene las letras y los títulos muy comprimidos y apretados entre sí, lo cual dificulta la lectura. Por otro lado, es creativa en el sentido que utiliza colores llamativos como el verde fosforescente y logra llamar la atención del lector. Su formato es diferente al resto de páginas web comunes ya que para buscar el 
contenido hay que mover la página de izquierda a derecha en lugar de ir de arriba hacia abajo. Además, tiene una columna en la cual expone los tuits más llamativos e importantes sobre el tenis. Por otro lado, la información que publica consiste principalmente en los resultados de los campeonatos y los rankings de los jugadores.

Luego de analizar las diversas páginas web mencionadas se llegó a las siguientes conclusiones. En primer lugar, la selección de colores define la personalidad de la web. A menos colores utilizados, se obtiene una página elegante, de buen agrado visual y ordenada sin distraer la lectura del usuario. Además, los colores fosforescentes generan incomodidad en la vista de los usuarios. En segundo lugar, hemos notado la importancia de la tipografía utilizada ya que de eso va a depender mucho la legibilidad. También, es importante el espacio entre las letras y palabras ya que si estas están muy separadas o muy juntas, dificultan una lectura rápida y sencilla.

Como tercera conclusión, se notó que funciona bien utilizar más imágenes y videos en lugar de texto, ya que facilita la lectura y llama más la atención ya que nuestro target es muy visual y se cansan cuando hay mucho texto y pocas imágenes.

Por último, hay que encontrar un equilibrio entre los colores utilizados para que no aburra al usuario o lo canse y cree una buena experiencia visual.

\section{Logotipo}

Luego de crear varios logotipos diferentes, se testeó con varios de los tenistas profesionales peruanos, tanto damas como varones, algunos entrenadores jóvenes de tenis y otros aficionados al deporte que son jóvenes adultos entre 18 y 35 años, a fin de poder elegir el mejor logotipo posible para nuestra marca y página web. La prueba la realizamos mediante Facebook y se contó con una muestra de 20 personas en total entre profesionales de tenis (jugadores como entrenadores) y aficionados al deporte.

El testeo contó con 10 opciones diferentes de logotipos que serán presentados a continuación: 


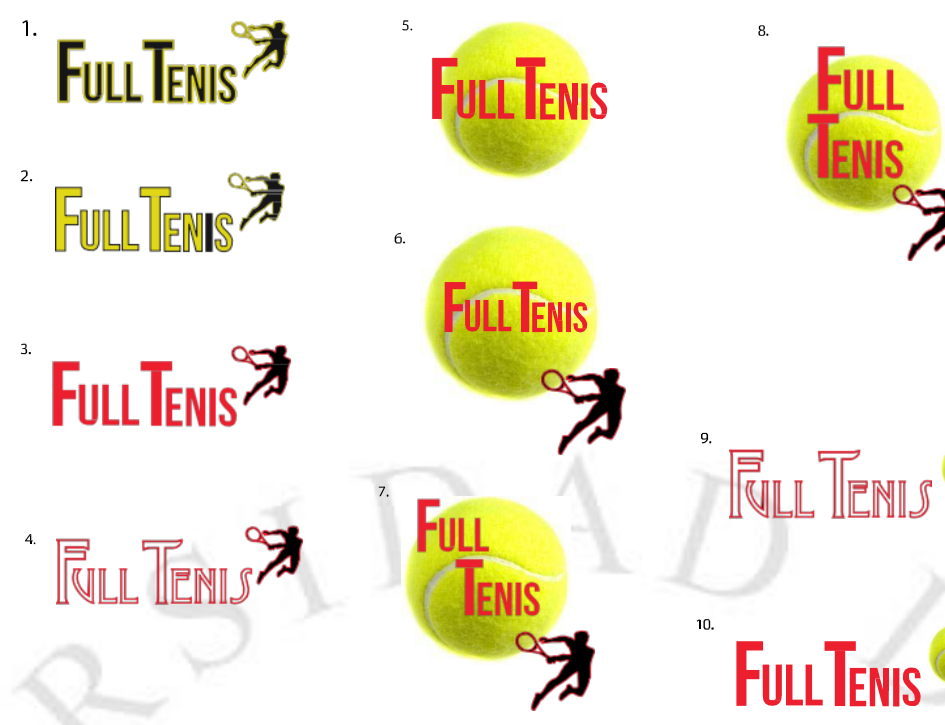

La opción con más votos fue la número 7 con doce votos, seguida por la opción número 1 con cinco votos. Las opciones 3,8 y 10 recibieron tan solo un voto cada una.

\section{- Opción ganadora (número 7):}

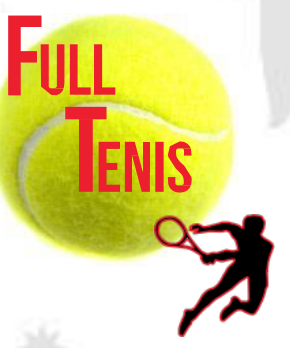

se

ejecutó

este

Los resultados de la encuesta indicaron que esta opción era la más legible, divertida, original y fácil de recordar a diferencia de las demás que eran más sencillas. Además, los colores utilizados estaban relacionados tanto al deporte como al Perú. Por ello, fue la opción con la que

La tipografía utilizada es Bebas Neue. Esta tipografía al ser de líneas rectas le da a la marca y página orden, elegancia, disciplina, además de firmeza, que son características del tenis, por lo tanto, lo evocan de una manera indirecta.

Se utilizó el color rojo por ser llamativo y evocar al Perú ya que es el color principal de la bandera peruana. Además, al utilizar una pelota de tenis se genera movimiento y el color amarillo causa atención, además de evocar al tenis. El personaje presente en el logotipo alude a todos los tenistas peruanos como si ellos fueran parte del logo y así se busca crear que el público objetivo logre identificarse con la marca desde el momento 
en que miran el logotipo. La mezcla de color rojo, negro y amarillo crean contraste, por lo tanto, buena legibilidad y así llama la atención del público.

\section{Host y dominio}

El siguiente paso fue comprar el dominio. Koky recomendó comprar el dominio .com ya que es un dominio de nivel superior genérico el cual es utilizado por sitios web comerciales y no comerciales. Costó sesenta dólares, lo cual no es un monto muy elevado para un buen dominio y hosting básico. Decidimos comprar un dominio y no usar uno gratis ya que según digitalserver.com: "Tener un host y dominio gratis es tener una casa en el aire, pues podemos realizar las cosas hasta un momento dado pero luego podemos desaparecer como por arte de magia". Esto nos indica que los dominios gratis no son seguros y además nos explica que "La capacidad de almacenamiento de datos es limitada", puede haber una "pérdida de información por mal funcionamiento o colapso de las páginas vecinas" "y "el tiempo en el que puede estar en funcionamiento es incierto y puede desactivarse en cualquier momento". Por lo tanto, la manera más segura para que la página perdure sin perder la información y se mantenga en el tiempo fue comprar nuestro propio dominio y host.

Además, la compatibilidad del .com es internacional, por lo tanto, nos da mayor amplitud para poder visualizarla en cualquier lugar dentro y fuera del Perú.

\section{Contenido}

En cuanto a la distribución del contenido de la página hay varias pestañas. Cada una tiene un título diferente y un contenido único que logra incluir toda la información pertinente de manera ordenada. Además, en el lado superior izquierdo de la página, existe una columna en donde se publican las últimas noticias más importantes y curiosas de la semana, las cuales son redactadas por nosotras mismas. También, contamos con una pestaña, la cual se llama contacto, donde las personas que tengan alguna duda o pregunta, podrán enviarlas y se las contestará a la brevedad posible. Joe Pulizzi, fundador del instituto de Marketing de Contenidos en Estados Unidos, describe el marketing de contenidos como: "Una técnica de marketing de creación y distribución de contenido relevante y valioso para atraer, adquirir y llamar la atención de un público objetivo bien definido, con el objetivo de impulsarles a ser futuros clientes". (2004) Es por esto que no es suficiente tener una página web bonita, es decir, agradable visualmente, sino contar con contenido importante. 
También, la página "40 de fiebre" que habla sobre el Marketing de Contenidos coincide con lo afirmado por Joe Pulizzi, mencionando que: "El propósito del marketing de contenidos es atraer y retener a esos posibles clientes a través de un contenido relevante y valioso".

A continuación, haremos una descripción del contenido incluido en la página web. Full Tenis Perú es una página informativa e interactiva que contiene las siguientes divisiones:

\section{Inicio}

Esta sección tiene como objetivo mantener al público actualizado sobre lo que está ocurriendo en el tenis, tanto nacional como internacional, así se enteran de las últimas noticias del deporte blanco.

Esta sección aparece por defecto al ingresar a la página donde se puede observar un carrusel en el cual aparecen imágenes importantes y recientes del tenis peruano e internacional, además de videos. Luego, en la parte inferior, se pueden ver las últimas actualizaciones del contenido de la página web y las últimas noticias de este deporte tanto nacional como internacional.

\section{Tips}

Con esta sección buscamos brindarle apoyo a los fanáticos del tenis para que sientan que la página se interesa por ellos, la cual está pendiente de sus necesidades para así poder darles lo que les gusta y satisfacerlos. Además, esta información brindada les puede ser muy útil a la hora que ellos jueguen este deporte y puedan así mejorar su técnica. Esta sección cuenta con siete divisiones con un submenú donde la persona que navega por la página puede encontrar diferentes opciones de consejos como preparación física, elección de raqueta adecuada, alimentación para tenista, consejos de otros grandes tenistas, tips para tener confianza, tips de cordaje y consejos para ser un buen restador.

\section{Tenistas Peruanos}

Con esta sección se busca el reconocimiento del público ante los mejores tenistas nacionales y destacados a nivel internacional que representan a nuestro país en diversos torneos del año. Además, buscamos crear conciencia en la FDTP (Federación Deportiva Peruana de Tenis) para apoyar a nuestros jugadores, ya que muchos de ellos no tienen los recursos económicos necesarios para competir en los países fuera del 
Perú y así se desperdicia mucho talento peruano; es decir, jugadores con mucho potencial que por tener escasos recursos pierden la oportunidad de sobresalir y otros de progresar en su juego, por la falta de horas de entrenamiento, al no poder pagarlas. Esta sección se divide en cinco, cada una tiene el nombre de un tenista peruano profesional y brinda información sobre este. Hay una pequeña reseña de cada uno, imágenes, biografía y la lista de sus títulos profesionales obtenidos. Estos son: Duilio Beretta, Mauricio Echazú, Bianca Botto, Sergio Galdós y Duilio Vallebuona.

\section{Academias}

En esta pestaña se ha seleccionado a las academias de Tenis de Lima agrupadas por distritos, se ofrece la opción de contactar con la entidad y saber si esta cuenta con una web o una página en Facebook. Además, sigue el patrón de las demás pestañas teniendo un submenú de seis distritos.

El propósito de esta sección es fomentar el tenis y lograr que los fanáticos del tenis que desean aprender a jugarlo o que ya aprendieron pero quieren retomar con sus clases, tengan a la mano información de lugares en los que pueden ir a tomar clases y cuáles son los lugares más cercanos a sus casas, ya que las academias están divididas por distritos, de manera que facilita la lectura al usuario.

\section{Torneos}

Esta pestaña tiene el submenú de Torneos Nacionales de Menores, Torneos Internacionales ATP y Torneos Internacionales WTA con los rankings y datos más actualizados.

Esta sección permite que los tenistas nacionales menores y sus padres puedan ver las fechas de todos los torneos que se aproximan y estar atentos para inscribirse a tiempo, gracias al haber colocado la fecha de inscripción de cada torneo. Además, también hemos linkeado la página web oficial de los torneos internacionales (ITF) para que nuestros tenistas puedan ver cuándo les toca un torneo y qué giras elegir. También aparece toda la información de inscripciones.

\section{Videos}

Esta sección tiene diferentes tipos de videos para cumplir con las expectativas y diferentes demandas que puede tener un fanático del tenis, ya sea interés nacional como por ejemplo un video de Duilio Beretta, como también puede ser internacionales donde se ve la copa Davis Perú - Chile 2015, entre otros contenidos. De este modo, 
seguimos de alguna manera promocionando a nuestros talentos nacionales para que sean apoyados por todos los fanáticos del tenis.

\section{Contacto}

Esta pestaña permite al internauta ponerse en contacto con Full Tenis Perú a través de un correo electrónico que tiene esta plataforma, pues se considera de relevancia el feedback y también buscar una fidelización con esta página. Que se vea como algo cercano donde uno puede entrar y sentirse cómodo, además que permite resolver consultas o dudas. Si diversas marcas quieren poner publicidad en Full Tenis Perú pueden hacerlo al ponerse en contacto mediante esta sección.

Además, esta página web tiene otro menú localizado en una barra blanca, en la parte superior de la página con otras pestañas como: Noticias Internacionales, Noticias Nacionales y los cuatro campeonatos más importantes del tenis mundial del año, los "4 Grand Slams": Australian Open, Roland Garros, Wimbledon y US Open.

Por otro lado, hemos creado la página con una propuesta visual e interactiva, es decir, Full Tenis Perú es una página muy visual al contener más imágenes y videos que texto. Esto vuelve a la página muy llamativa y genera agrado visual por parte del lector que va a desear quedarse por mucho rato en la página y navegar sin aburrirse en comparación a otras páginas que priorizan el texto en lugar de la imagen.

Hoy en día, vivimos en una época en la cual todo "entra por los ojos", por lo tanto, si uno busca tener clientes fieles y crear lealtad de marca, el contenido tiene que abarcar muchas imágenes y videos para así lograr captar la atención del público. Asimismo, las secciones están muy bien ordenadas y es fácil de buscar la información que uno desea.

También, los colores principales utilizados en la página (rojo, amarillo y negro) le dan elegancia y un aspecto visual limpio y ordenado de fácil lectura al utilizar pocos colores que combinan armónicamente entre sí, a diferencia de otras páginas web que utilizan muchos colores que cansan la vista del usuario y le crea un aspecto desordenado y difícil de entender. Los colores utilizados son muy llamativos y remiten al deporte y al Perú, por ejemplo, el rojo remite a nuestro país y el amarillo al tenis.

Adicionalmente, es muy interactiva ya que permite que los usuarios dejen sus comentarios respecto a cada publicación y pueden interactuar entre ellos, gracias al espacio de comentarios que se encuentra al final de cada publicación. También, la página les permite contactarse con los creadores y administradores de esta mediante 
correos electr6nicos y nosotras les respondemos a la brevedad posible generando asf una rapida comunicaci6n de doble via. 


\section{LOGROS Y RESULTADOS}

El primer logro fue crear la página tal cual se imaginó. Es decir, se construyó la infraestructura esperada, se obtuvo el diseño elegante, único y creativo con colores relacionados al deporte. Además, se logró que la paleta de colores elegida remita tanto al tenis como al Perú, que era uno de los propósitos.

Se logró que la página sea propia, organizada y ordenada, la cual contiene toda la información que se trazó al inicio del proyecto y está distribuida de una manera que permite la fácil lectura al usuario y es agradable visualmente.

Se enfocó el contenido que creamos en el tenis nacional, pero sin dejar de lado lo más importante del tenis internacional que fue el objetivo principal del proyecto. Esto se refleja en que la mayoría de las secciones de la página dan información sobre el tenis nacional. Por ejemplo, los tenistas peruanos más destacados, academias locales, videos sobre los jugadores nacionales, etc. Sin embargo, no hemos dejado de incluir las noticias más importantes del tenis mundial.

En cuanto al alcance obtenido en la página Full Tenis Perú, logramos 3193 visitas en la página web de noviembre 2016 hasta marzo 2017 y en menos de dos semanas, alcanzamos más de 200 "Me gusta" sin haber invertido en publicidad para la página en Facebook. El primer día la página alcanzó casi 100 "Me gusta" y en el transcurso de esa y la siguiente semana alcanzamos y pasamos el objetivo. Todo esto se dio mediante conversaciones entre amigos que compartían la página.

También, se logró que dos de los tenistas más destacados del Perú nos escriban y nos comentaron lo siguiente:

Hemos podido validar y lograr este objetivo mediante unos comentarios que nos hicieron llegar algunos tenistas profesionales del Perú:

"Quiero felicitarlas por la pagina que han hecho, me parece súper completa y me gusta bastante también que hayan hecho una sección exclusiva de los tenistas peruanos y sobretodo gracias por incluir mi trayectoria, esto me ha motivado y hecho sentir valorado " (Duilio Vallebuona, 2017) 
"Que paja la página, me gustó mucho ver una web con este perfil y me parece recontra completa desde la primera impresión, sigan adelante". (Mauricio Echazú, 2017)

Por otro lado, una dificultad que se presentó al inicio de la creación de la web fue iniciar los esfuerzos en una plantilla. Buscamos por varias semanas distintas opciones de plantillas posibles pero ninguna se acomodaba a la arquitectura deseada. Por ello, se tuvo que buscar a un programador para que personalice una web y eso volvió el trabajo un poco más complicado ya que dependíamos del programador para subir el contenido al no conocer el lenguaje de programación (HTML). Sin embargo, una ventaja de trabajar con un programador, es que esa página web creada es propia y puedes manipularla a tu gusto.

Un fracaso que tuvimos en la creación de la página es que las fotografías que hemos usado en la web, no son de la más alta calidad. Esto se debe a que hasta el momento no se ha tenido tiempo para reunirnos con los tenistas más reconocidos por temas de horarios que no coincidían, entonces se han utilizado algunas fotografías ya existentes. Sin embargo, ya se están iniciando las coordinaciones para realizar las sesiones fotográficas con los tenistas. 


\section{LECCIONES APRENDIDAS}

En el presente punto se mostrará las experiencias y lecciones aprendidas a lo largo de la planificación, ejecución y alimentación del proyecto presentado.

En primera instancia, se tuvo que armar una planificación de trabajo para que no se acumulara todo a último minuto, para lograr un resultado exitoso y sin malos ratos.

También pudimos notar que tener un plan de trabajo con un calendario nos ayudó a organizarnos en cumplir y presentar avances, como también dedicar un tiempo a la revisión y análisis de lo realizado. De esta manera nos dimos cuenta que una vez que se hacía algo, luego con otra mirada en otro contexto podía mejorarse la idea propuesta. En esta organización nos fue muy bien ya que se trabajó de manera muy ordenada y se cumplía con lo propuesto, es decir, si se había quedado tener tal contenido en alguna fecha, se cumplía de modo que podíamos confiar una en la otra y eso creó un ambiente bonito y armónico de trabajo.

Además, se notó que para un buen trabajo en equipo, es necesario un real compromiso por parte de todos los miembros del grupo. Por lo tanto, consideramos que para este trabajo hay que saber organizarse y es muy importante contar con un calendario y una planificación previa antes de empezar a crear el producto final.

Por otro lado, se aprendió en confiar en cada una como dupla de trabajo, sabíamos que cada una tenía horarios distintos, sin embargo, estuvimos tan comprometidas en realizar un buen trabajo que pudimos notar que podíamos trabajar conjuntamente confiando en la labor de cada una.

Además, aprendimos que el involucramiento que pone cada una en esta web es parte fundamental ya que no hay nadie más que genere o agregue contenido, si esta web está alimentada es por el trabajo que venimos realizando, por cada acción que hemos ejecutado.

También, en un inicio, nos costó encontrar una persona de confianza que sea el programador de nuestra página web. Se investigó y averiguó entre amigos, familiares y conocidos hasta que finalmente se dio con un experto en páginas web que ya le había creado una web a un amigo nuestro con buenos resultados, por lo tanto, decidimos pedirle su apoyo. Esta persona fue la encargada de publicar el contenido que nosotras 
creamos y usar el diseño que elegimos para la página. Así, logramos encontrar a Koky, una persona honesta y comprometida que no cobró muy caro en comparación al resto de programadores. Su trabajo siempre fue impecable; entregaba a tiempo y siempre nos aconsejaba, muchas veces de acuerdo y otras no, pero en general fue una bonita experiencia trabajar con él. Por ello, creemos que es muy importante contratar siempre a alguien de confianza y disciplinada para de esta manera no pasar malos momentos ni decepciones. Asimismo, se resalta el hecho de que Koky era un experto en programación de páginas web. Sus opiniones y consejos profesionales siempre fueron objetivos haciéndonos notar varios puntos de mejora, los cuales fueron aplicados en la web.

Otra lección aprendida en este trabajo fue que algunas veces, cuando se le decía a Koky que publique algún contenido que se había creado y suba alguna imagen, muchas veces por olvidarnos de revisar, encontrábamos después de algunos días que lo pedido no había quedado como nos gustaba. Por ello, se pudo aprender con eso que siempre hay que revisar que el programador haya publicado correctamente lo que se le encomendó y no suponer que lo va a publicar como uno quiere. Es decir, siempre hay que hacerle seguimiento a lo que se solicita para obtener el resultado esperado. En ocasiones, se notó que el orden de las cosas estaba diferente a lo que se proponía, por ello, siempre es bueno revisar cada material que se sube a la web. Esto no significa que el programador lo haga mal, sino que muchas veces puede entender algo distinto a lo que se desea o no nos llega a entender completamente. Con esto, se aprendió que cada persona interpreta los mensajes de manera diferente, por lo tanto, para que la comunicación, en este tipo de situaciones sea exitosa, los mensajes deben ser directos, claros, sencillos y si es posible aterrizarlos en ejemplos. Además, siempre es bueno preguntarle al receptor si tiene alguna duda o consulta sobre lo encargado, para evitar malos entendidos y además aprovechar en recibir una retroalimentación sobre lo que se delega. Tal como se mencionó previamente, es en estas ocasiones cuando recibimos consejos y aportes por parte del programador.

Esto se aprendió en nuestras primeras publicaciones cuando le solicitamos al programador que suba una serie de noticias y unas fotos. Confiando en que iba a realizar el trabajo como lo imaginamos, nos dimos con la sorpresa de que las fotos no estaban en el tamaño que esperábamos y las noticias no se encontraban publicadas cronológicamente, ahí entendimos que quizás el mensaje no había sido tan claro como creíamos y a partir de ese momento cuidamos la comunicación con nuestro programador, detallando nuestros requerimientos. Además de realizar 
instantáneamente el seguimiento respectivo en cuanto se nos indique que la publicación se realizó.

Por otro lado, se aprendió que el trabajo de hacer una página web no es algo sencillo, ya que todo aquello que se publica es una responsabilidad asumida por nosotras y eso está en la web donde todos lo pueden leer y hasta guardar. Por ejemplo, en este caso, cada publicación fue hecha por nosotras, no se le puede pasar al contenido ni un título que copies y pegues de otra noticia porque esto sería plagio y tu contenido debe ser original e ingenioso, se debe redactar bien porque si ven faltas ortográficas también es nuestra culpa por no revisar antes de publicar. Se tiene bastante responsabilidad al manejar una página web de deportes que esté al alcance de todos. Más aún que hoy en día vivimos en la era digital, es decir, toda la información se encuentra en la web al alcance de todos los usuarios, por lo que un error puede hacer ruido y dañar la buena imagen que se consigue durante largo tiempo con bastante trabajo y dedicación. Es por esto que hay que tener mucho cuidado en qué publicar y estar cien por ciento seguros que sea información verídica, para no perder credibilidad.

Además, se aprendió a ser selectivas, no puedes sobrecargar una página web de información, imágenes y videos porque aturde al lector, dificulta la lectura y puede confundir al usuario. Tampoco puedes dejarla muy simple porque las personas se pueden aburrir y pensar que está incompleta. Es importante encontrar un balance entre ambas partes mencionadas para que el usuario tenga una experiencia agradable en la web. Para lograr esto, uno debe ir probando y preguntando, según el público objetivo, qué es lo más acorde para este.

Por otro lado, se aprendió que la experiencia del usuario en la página web es muy importante ya que eso es lo que determinará si este vuelve a entrar a la página. Si la persona que visita la web se siente cómodo con la lectura, información, imágenes, videos y la forma en sí de la distribución del contenido esto puede generar que en base a su experiencia recomiende a otras personas la web. Esto genera que se haga más conocida ya que la fuente de difusión más confiable es el boca a boca.

En base a nuestra propia experiencia nosotras también realizamos ello, cuando hacemos o descubrimos algo que nos agrada lo compartimos como noticia o dato con las personas que frecuentamos o sabemos que tienen los mismos gustos. Por ello, al pertenecer al grupo objetivo que nos referimos podemos usar nuestra propia experiencia como herramienta para mejora. $O$ en su defecto, cuando se tiene una 
experiencia desagradable o dificultosa también se comunica y esta es mucho más rápida y se difunde con mayor facilidad.

Por tanto, se considera relevante el hecho de que la persona que visite la web tenga una experiencia agradable en ella. Ya que como se ha mencionado en la introducción al trabajo, nuestra web es única en tenis peruano, por tanto, el punto de comparación es con webs internacionales y debemos cumplir los estándares de estas y expectativas de las personas.

Otro aspecto que se aprendió fue el tomar decisiones relevantes, pues hay mucha información, diferentes caminos y maneras para publicar y mostrar algo, por tanto, la decisión que se toma debe cumplir con la línea gráfica propuesta para no romper con el esquema visual. Todas estas decisiones son de uno porque el programador puede aconsejarte, pero al fin y al cabo uno tiene la decisión final según lo que se cree que puede ser mejor. Por lo que, al ver nuestra página web, concluimos que se aprendió a tomar buenas decisiones que nos llenan de orgullo.

Por otro lado, se aprendió sobre los tiempos de vida de un dominio, costos y renovación gracias al apoyo de nuestro programador Koky, asimismo, nos mostró que cada dominio tiene una serie de permisos de administración y esto puede en ocasiones limitar los cambios visuales o estéticos de la web. Por ejemplo, desde un inicio que creamos el diseño de la web, esto determinó los permisos que podríamos tener como la plantilla donde se crearía esta. El orden donde aparecerían las pestañas de información que deseábamos incluir.

Además, notamos que a pesar de tener una sección de contacto donde se nos puede escribir, esta comunicación sería de modo privado entre usuario y administrador de la web, en este caso, nosotras. Sin embargo, nos pusimos en el caso de que la comunicación pueda ser pública sin incomodar a otros usuarios. De esta manera creamos la cuenta de Twitter de la página, la cual está linkeada en la parte superior derecha con el ícono de esta red social. Esta función nos sirvió para mandar mensajes a nuestros seguidores que son las personas interesadas en el tenis, web o deporte, como aficionados o tenistas profesionales. De esta manera podrán enterarse del contenido relevante con una notificación a su celular, además esta plataforma permite que "retuiteen" y manden mensajes y la comunicación es abierta, directa y simple para todos los internautas que participen. 
Además, se descubrió que el alcance puede incrementar complementándose en esta plataforma, pues no todas las personas visitan necesariamente la web de algo en específico, sino también siguen el contenido por plataformas que frecuentan diariamente, en este caso Twitter.

También se aprendió que no debemos conformarnos con lo logrado, pues siempre hay una oportunidad de mejorar, en este caso nosotras lo relacionamos con la vinculación a la red social Twitter, esperamos próximamente manejar una red adicional como Facebook. Sin embargo, también hemos experimentado que, para manejar contenidos y redes, se necesita de tiempo extra y que si deseamos continuar creciendo deberíamos incluir a una persona adicional al grupo que se encargue de manejar las redes sociales como community manager mientras nosotras nos encargamos de alimentar al web en contenido y Koky de ejecutar los cambios técnicos en la web. Este aspecto lo tenemos claro, ya que por más que cada una tenga ganas de crecer la web y realizar nuevas y diferentes actividades, se debe tener orden y un plan de trabajo.

Cada persona debe tener un rol específico porque si todos hacen lo mismo a la vez pueden aparecer errores y estancar el avance. Esto nosotras lo hemos aprendido dividiéndonos ciertas labores, algunas sí en trabajo conjunto y otras veces cada una en su rol. Por ejemplo, Milena es tenista por lo que los contenidos de consejos, tips y entrevistas a expertos en tenis fue tarea de ella. Por otro lado, Michelle de Asin es aficionada al diseño y notas periodísticas, de esta manera Michelle redactaba noticias del deporte y revisaba la parte gráfica visual de la web.

Por otro lado, mientras avanzábamos con la creación de la página web, nos dimos cuenta que más adelante podría ser viable conseguir auspicios de muchas marcas de deporte reconocidas internacionalmente como por ejemplo Nike, Adidas, Reebok, Babolat, Wilson, etc. $Y$ así poder generar concursos entre los usuarios aficionados al tenis para que se ganen ropa, raquetas, zapatillas, entre otros. Para lograr conseguir estos auspicios, nosotras les ofreceríamos a estas marcas, publicitar sus productos en nuestra página. Es decir, nosotras les haríamos publicidad en nuestra página a cambio de recibir un auspicio. Esto va a contribuir a generar mayor tráfico en la página y hacerla más conocida. Esta es una manera de incentivar a que cada vez más personas confíen en nosotras. Si bien este no fue nuestro objetivo principal del trabajo, fue una oportunidad que apareció durante el proceso y que no debemos desaprovechar. Con esto se aprendió que siempre aparecen ideas nuevas e interesantes durante el proceso de un trabajo y que hay tomar en cuenta ya que puede ser una gran oportunidad para 
la repercusión del proyecto. Además, no debemos quedarnos con lo que tenemos, sino siempre pensar en qué más se puede hacer. Así nació la idea recién mencionada como muchas otras.

También, se aprendió que siempre es bueno pedir una segunda opinión a terceros ya que estos no están involucrados en el trabajo, por lo que así podemos obtener una mirada fresca de alguien que va a ver el trabajo por primera vez. Es necesario tomar en cuenta este tipo de opiniones ya que la primera impresión es muy importante y casi determinante para el éxito de un proyecto. Nos dimos cuenta de esto cuando ya la página web estaba creada y le pedimos a una amiga tenista, que nunca antes había visto el proyecto, que nos diera su opinión sobre la web y nos comentó que todo estaba lindo pero que la posición del logo no le cuadraba, que la hacía confundirse ya que no sabía si era el logo de nuestra marca o de una marca de tenis. Gracias a este consejo, se analizó la posición del logo y preguntamos a unas cuantas personas más y efectivamente, era un poco confuso. Por ello decidimos cambiar la posición del logo y quedó en un lugar perfecto. Gracias a esta experiencia, recalcamos la importancia de consultar a una persona externa una opinión.

Además, se aprendió a aceptar críticas por parte de nuestros profesores, del experto en páginas web y hasta del público en general. Muchas veces no se va a estar de acuerdo con todo, pero hay que tomar las críticas de la mejor manera y como oportunidades de mejora. No siempre se tiene que hacer todo lo que te dicen, pero si tomarlo en cuenta, pensarlo, analizarlo y luego tomar una decisión. Una vez que aprendimos esto, decidimos aplicarlo al final de la creación de la página. Una vez que la web estuvo lista, antes de enviársela al profesor, se la mandamos a 50 personas externas dentro del público objetivo al que va dirigida la página para que nos dieran su opinión y críticas constructivas. Con el feedback que obtuvimos de parte de ellas, pudimos mejorar algunas cosas las cuales no nos habíamos dado cuenta antes como, por ejemplo, algunos detalles que no nos habíamos percatado o incluso algunas fotos que no estaban muy nítidas, entre otras cosas. 


\section{REFERENCIAS}

Salinas Cornejo, J. (2007) Tenis al maximo TV, Perú (www.tenisalmaximo.tv)

Federacion Deportiva Peruana de Tenis, S.F (http://tenisperu.com.pe/tenis campo/)

International Tennis Federation, S.F (http://www.itftennis.com/home.aspx)

Women's Tennis Association, S.F (http://www.wtatennis.com/)

Asociación de Tenistas Profesionales, S.F (http://es.atpworldtour.com/)

La Web del Tenis, S.F (http://www.lawebdeltenis.net/)

TenisWeb, S.F (http://www.tenisweb.com/)

Tenis Senior,S.F (http://www.tenissenior.com/)

Tennis One, S.F (http://www.tennisone.com/)

We are Tennis, S.F (http://www.wearetennis.com/en UK/)

Niumedia.mx, (2014) San Luis Potosí, Mexico (niumedia.mx)

Alvarez, Javier (2011) Perfil del adulto joven de Lima Metropolitana de IPSOS

Jimdo (2012) España (http://es.jimdo.com)

Santa Maria Fiori, (2014) (http://www.staffcreativa.pe/blog/teoria-del-color-

disenadores/)

Graglia Cristian (2012) La importancia del diseño en los sitios web

Gil Manuel (2012) Colombia, ¿Es realmente importante un buen diseño web?

Valdés Xavier (2014) La importancia del diseño web

Ortiz Sebastián, S.F La percepción visual en el tenis

Jobs Steve, S.F Emphaty Broker

Digitalserver, S.F (digitalserver.com)

Pulizzi, Joe, (2004) "40 de fiebre" 


\section{ANEXO \\ ANEXO 1: Entrevista a profesional de tenis \\ Duilio Vallebuona (N. 1054 del mundo)}

1. ¿Conoces páginas Web sobre tenis?, ¿cuáles?, ¿qué opinas de ellas?

Sí, conozco de diferentes lugares tanto nacionales como internacionales. En las nacionales puedo mencionar a dos muy buenas: Tenis al máximo y TenisPerú. La primera es de las páginas actualizadas que hay en el Perú y la segunda es la página de la Federación Peruana de Tenis. Ambas con muy buena información y siempre actualizando. En las internacionales podemos encontrar atpworldtour.com que es la página más completa que vas a poder encontrar sobre el tenis mundial al igual que la página itf.com Ellas son las dos con más información que se puede encontrar.

\section{2. ¿Cuál página web de tenis te parece la más completa?}

La página web más completa que hay es sin lugar a dudas atpworldtour.com. En esta página podemos encontrar todo tipo de información que se necesita. Además que se actualizan los cuadros de los torneos internacionales inmediatamente. Además, hay un livescore de todos los partidos del ATP.

\section{3. ¿Qué crees que debería tener una página web sobre tenis para que sea completa?}

Una página web para que sea completa debe tener la información de los jugadores al cual la pagina este enfocada. Además de actualizar constantemente los torneos y scores de los torneos más relevantes del año.

4. ¿Te importa el diseño de la página web a la hora de entrar a una?, es decir, ¿te parece relevante el diseño y los colores utilizados en una página web o prefieres el contenido?

Lo que interesa de una página web es encontrar rápidamente lo que uno busca, no estar paseándote por toda la página sin encontrar lo que uno busca. Obviamente el color y el formato debe ser agradable para las personas porque pierde interés del lector si no le llaman los colores o el formato, pero no se puede descuidar el contenido, eso es lo más importante.

5. ¿Qué secciones te gustaría que tenga una página web de tenis? 
Me gustaría que tenga secciones de diferentes jugadores, torneos, fotos de los torneos, entrevistas, videos de cada jugador (éste último podría ser una innovación porque no hay páginas que abajo de la descripción del jugador tenga un video), por ahí algunos tips para mejorar golpes. Más que nada eso.

\section{ANEXO 2: Entrevista a experto en páginas web}

\section{Frederick Corazao}

\section{1. ¿Qué tan sencillo es hacer una página web?}

Te voy a tratar de responder esto desde dos puntos de vista: el mío y el de un individuo sin conocimientos de web. Por mi lado, no es muy complicado. Yo diría más bien que es un reto. Tienes que casar el diseño con la funcionalidad, la programación y la interfaz con el usuario. Tienes que definir bases de datos, pensar en qué puede necesitar el cliente más adelante, cómo quieres que la web responda a los usuarios, etc. Todo esto no es difícil, pero requiere de varios años de experiencia para poder hacerlo bien la primera vez y no tener que cambiar la web o parcharla más adelante. Ahora, esta el otro punto de vista, una persona que no sabe hacer webs, que me imagino es tu caso.

Exacto, para una persona común, una web es un montón de texto e imágenes que te dan información. Facebook es un motón de fotos de qué están comiendo tus amigos y dónde están pasando el verano. Pero atrás de eso hay millones de líneas de código, hay toda una ciencia atrás de por qué las fotos salen de ese tamaño, porque el texto es de ese color, porque los botones están donde están, etc. $Y$ ahí nace el primer choque que tienen muchos clientes con sus proveedores de desarrollo web: "es muy caro, si solo son 5 páginas".

Te pongo un ejemplo que siempre le doy a mis clientes cuando se espantan por el precio. Imagina que tienes una máquina gigantesca y complicadísima que fabrica pan y deja de funcionar. Llamas al servicio técnico y viene una persona con su caja de herramientas. Mira la máquina por todos lados, la observa, se acerca, saca un destornillador y ajusta un tornillo. Listo señorita, acá está la factura, son S/.5000. Lo más seguro es que tu reacción sea de furia por tener que pagar tanto por ajustar un tornillo, pero, tu no sabías cuál tornillo ajustar.

Es lo mismo con una web. Se ve simple y fácil y bonita por fuera, pero tienes que saber cómo hacerla.

\section{2. ¿Dónde me conviene hostearla?, ¿por qué?}


Yo siempre recomiendo Exclusive Hosting a mis clientes que es un hosting en Estados Unidos. Yo tengo alojada mi web y también algunas de mis clientes ahí desde hace más de 6 años, si mal no recuerdo. Nunca he tenido problemas de baja de servidor (downtime o mantenimiento). Además, el servicio es A1. En cuanto a servicio técnico es una maravilla, nunca demoran en contestar más de 20 minutos y casi nunca he tenido problemas con ellos. De hecho, la mayoría de mis contactos a servicio técnico han sido por algo que yo había entendido mal. Además del buen servicio, el precio es súper económico. El costo por un hosting básico es menos de $\$ 36$ anuales y eso incluye espacio y tráfico ilimitado. Es muy barato, especialmente comparado a otras opciones locales. Tengo clientes que pagaban hasta $S / .200$ anuales por un hosting que no les funcionaba muy bien.

3. ¿Qué programa sería el más adecuado para hacer una página web?, ¿por qué razón?

Depende mucho del nivel de conocimientos que tengas. Hacer una página web, en esencia, es programar. Escribir miles de líneas de código para que la web se vea y haga lo que quieres. Encima de eso, por así decirlo, van los textos, las imágenes, las animaciones o videos y todo el resto de contenido que quieras poner. Para esta parte usas unas herramientas como Photoshop, Illustrator o cualquier otro programa, pero de nuevo, eso es el "relleno". Lo que es una web es código, y honestamente, lo podrías escribir en bloc de notas sin problema. Yo uso Adobe Dreamweaver. Con ese programa aprendí a hacer webs hace muchos años, aún antes de aprender los lenguajes de programación. Verás, Dreamweaver, así como Muse y otros programas más te permiten hacer webs con "drag and drop", es decir, como si estuvieras armando una gráfica. Son herramientas que facilitan mucho el desarrollo de una web, pero tienen limitaciones y cuando conoces el lenguaje, es bastante más rápido hacerlo a mano. Yo sigo usando Dreamweaver porque, además de permitir armar la web como te comento, tiene un parte para escribir código, con sugerencias, autocompletado, pinta el código según lo que esté escribiendo, etc. Con eso me facilita bastante la vida.

4. ¿Me recomiendas que la haga yo que no tengo experiencia en hacer páginas web o debería contratar a alguien?

De nuevo, depende mucho de qué tan sofisticada vaya a ser. Por ejemplo, el cliente que te comenté antes, ella hizo la web sola y no estaba mal, pero eventualmente me contactó para hacer la parte de la programación, para poder 
administrar la web y no tener que modificarla cada vez que quiera cambiar algo. Por el tipo de proyecto que me cuentas, creo que si sería ideal que contrates a alguien para que te ayude a hacer una web profesional, que funcione bien $y$, sobretodo, y esto es un punto importantísimo, que se haga con un norte bien definido. Es infinitamente más fácil, económico y práctico hacer la web sabiendo a donde se quiere llegar, que tener que modificar una web existente para que cumpla otra función.

\section{5. ¿Dónde consigo esa ayuda?}

El mercado peruano es complicado en este tema. Hay 3 grandes grupos que te pueden ayudar.

Están las grandes agencias, publicitarias, de medios, digitales, etc. No tienen un nombre muy claro. Pero son grandes, llenas de programadores y diseñadores, con un gran equipo técnico y personas con todos los años del mundo de experiencia. El problema con estas es que son carísimas y cada vez que quieres hacer una consulta, un reclamo, pedir un cambio o alguna otra cosa, lo más probable es que te encuentres con una burocracia interna interminable. El que ve tu proyecto tiene que hablarle al diseñador para que él le explique al programador que hay que hacer y luego es teléfono malogrado. En los peores casos, te cobran por esto. Estas agencias generalmente viven de hacer trabajos a otras empresas enormes, como bancos, clínicas, etc. Que están un poco más acostumbrados a estos procesos largos.

Después están las agencias chicas y los freelance. Yo pertenezco a este grupo, así que mi opinión puede estar sesgada, pero te explico un poco cómo yo lo veo. Las agencias chicas y los freelance generalmente están, digamos, ajustados con sus cuentas. El mercado de webs es muy aleatorio y no siempre hay trabajo. Puedes pasar un par de meses con nada que hacer y luego en un mes te caen 5, 6 o 10 clientes. Eso significa dos cosas: primero, que amamos a nuestros clientes por sobre todas las cosas. No podemos darnos el lujo de ser sobrados o indiferentes porque nos interesa hacer un buen trabajo (crear portafolio), quedar bien con el cliente (crear referencias) y terminar rápido para poder hacer otro trabajo. Además de esto, las agencias chicas suelen tener no más de 4 o 5 personas trabajando. La verdad es que no se necesita más. Los freelance hacen todo solos o cuando están con mucha carga le pasan parte del trabajo a otro amigo freelance. Como te digo, hacer una web no es mucha ciencia, si sabes lo que haces. Las agencias grandes tienen un montón de gente porque sus proyectos son gigantes y porque tienen muchos proyectos simultáneos. 
Entonces, la ventaja que te ofrece trabajar con agencias chicas o freelance es que el contacto es directo con la persona que está viendo tu tema, el presupuesto es mucho menor y el trabajo se hace más rápido. La desventaja creo que es obvia, existe un riesgo de que te fallen. No sabes la cantidad de clientes que me han venido con historias de alguien que les hizo la web, desapareció del mapa y nunca pudieron modificarla porque el tipo se llevó los accesos. Incluso un par de clientes han tenido que cambiar de dominio (url) por este tema y empezar su posicionamiento desde cero.

Finalmente, está el tercer grupo. La gente de Wilson. No tengo mucho que decir de ellos excepto que no tienen una educación formal en el tema. Sus conocimientos de desarrollo web son primitivos, suelen usar plantillas y modificarlas mínimamente y tienen cero conceptos de diseño, marketing, publicidad, etc. El tema es que es baratísimo contratarlos y son muy rápidos (porque usan plantillas). Esta gente se tira abajo el mercado y a la larga terminan dañando a las empresas. He tenido varios clientes que han llegado con webs horribles y con dramas porque les hicieron mal las cosas, incluso algunos de esos clientes habían rechazado mi propuesta algunos meses antes por ser "muy cara" y se habían ido a Wilson.

Personalmente, te recomendaría una agencia chica o un freelance si puedes encontrar a uno de confianza. Esto usualmente es por contactos y recomendaciones. Suena raro, pero yo creo que es súper importante tener a alguien de confianza, con quien puedas hacer una conexión, para ver el tema de la web. Como no es una ciencia a veces es difícil explicar lo que uno quiere, lo que se puede o no hacer, las limitaciones y otros factores, y es mejor poder tener a alguien a quien explicarle las cosas o con quien tomarte un café y tomar decisiones.

Para encontrar uno es fácil, todos conocen a alguien que conoce a alguien que ha hecho alguna web alguna vez. Al menos el $90 \%$ de mis clientes llegan por recomendación.

6. ¿Crees necesario contratar a un diseñador gráfico, aparte de un programador de páginas web, para crear la página?

Creo que te he contestado todas las preguntas con "depende", pero si, depende de qué tan sofisticado quieras el diseño de tu web. Si tienes una idea más o menos clara de qué quieres hacer y cómo quieres que se vea, basta con ir donde una agencia chica o un freelance y preguntarles si hacen también diseño. Si te dicen que sí, les muestras referencias (otras webs similares como "inspiración") 
y les pides que te hagan algo así. Es ideal que el freelance sepa de diseño o que la agencia tenga un diseñador, para no estar creando cadenas de comunicación innecesarias. Es mejor que todo se vea en un solo lugar. Ahora, el diseñador solo estará presente en la primera etapa del desarrollo, ya que después los cambios y modificaciones casi seguro que serán solo a la programación, ya no a la estructura en sí de la web. Solo lo necesitarías llamar en el futuro si quieres hacer cambios, ampliaciones, etc.

ANEXO 3: Entrevista a profesor de Proyectos Digitales (Universidad de Lima)

\section{Montalvo}

1. ¿Qué opina sobre el proyecto, lo cree factible?

Sí, pero yo creo que es muy amplio y quieres cumplir con muchas cosas que de repente se te pueden complicar. Creo que deberías concentrarte en un objetivo más específico como por ejemplo, de brindar información y concentrarte en enfocar tus objetivos a ello. Tienes que enfocarte en tu público objetivo que no sea muy amplio, conocer el feedback de los consumidores en proyectos similares al tuyo para que pueda tener futuro. También podrías considerar de repente cambiar la página web a un blog que es más personal y menos complicado de realizar.

2. ¿Qué herramientas podría utilizar para una buena página web? Yo creo que como te dije anteriormente, deberías reducir la diversidad de información que deseas incluir. Es decir enfocarte en un solo objetivo y por ejemplo, contactarte con alguna marca de tenis que pueda ayudarte a elaborar tu proyecto y tú a

la

vez promocionarla.

3. ¿Cómo puedo llegar a mi público objetivo de manera efectiva? Para ello debes analizarlos y ver donde se encuentran en su mayoría, por ejemplo, en los clubes y academias de tenis, ¿puedes hablar con ellos?, ¿tienes acceso a clubes y academias en las cuales puedes ir y conversar directamente? Yo no conozco mucho sobre el tenis.

\section{4. ¿Qué estrategias digitales me recomienda utilizar?}

Primero deberías elegir un nombre original para tu marca que no se parezca a los ya existentes y luego crear su logotipo. Que sea un nombre original, diferente, novedoso, creativo y luego ver medios y testearlo para poder encontrar el mejor nombre posible. Podrías también ver la posibilidad de utilizar marcas de tenis ya 
existentes para hacerle publicidad en tu página y así captar más a tu público.

\section{5. ¿Le parece relevante este proyecto?}

La verdad que no se mucho sobre tenis así que no podría decirte con certeza pero siento como te dije anteriormente que deberías reducirlo o juntarte con alguna empresa y realizar la página para ellos, sino también podrías considerar en lugar de una página web, un blog.

6. ¿Cree que se presente alguna dificultad en la ejecución del proyecto? No es muy fácil hacer una página web para una persona que nunca ha hecho una, ¿quién la va a actualizar cada cierto tiempo?, ¿quién se va a encargar del feedback y de responder reclamos? Hay que tener en cuenta esas cosas.

\section{7. ¿Cómo podría lograr un buen posicionamiento?}

Bueno, siendo novedosa y creativa. Podrías tomar como ejemplo páginas ya existentes y tratar de hacer algo completamente distinto y llamativo. Teniendo un buen logotipo y nombre original que se diferencie completamente a los demás.

\section{ANEXO 4: Google Analytics - Visión general de la Audiencia}


Tocha ha usuar cs

1010: stimanes

Vel6่า goneral

- Nómeru dz visilas y ojurkes

tm

$\Gamma \mathrm{V}$

$\therefore, \therefore, \mathrm{V}$

\begin{tabular}{|c|c|c|}
\hline Eacraz & I b.urias & Nunerc dt vituue ox'çitiss \\
\hline 3.193 & 2.575 & 5.010 \\
\hline$, \ldots{ }_{-}, \ldots !, \ldots \ldots \ldots, \ldots, . .,{ }_{-}, \ldots{ }_{-}$ & $>5-5-$. & (n......... \\
\hline Poniliesimarist & 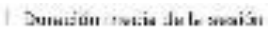 & \\
\hline 1,57 & 0 0p:01:51 & 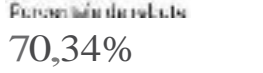 \\
\hline
\end{tabular}

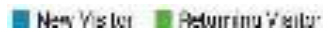

I:- :- - $=70,34 \%$

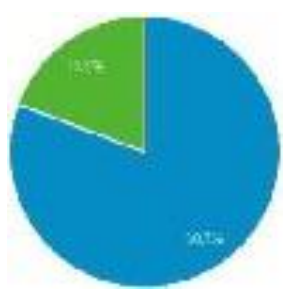

Siartuara ansmits

$811, \mathrm{fl} \%$

Flit

$\mathrm{t} \$ 1\left(1 \mathrm{Q}_{3}, \quad, \ldots \mathrm{S}\right.$ eJ

-. $\quad \mathrm{i}=\mathrm{MCl}$

- uili..ss.....

o. $\langle.\rangle \bullet^{\prime \prime \prime}$

- or.

- O..

.. "'" "'.; ,

- Ooilo

- itt.'It.oelll

- $r$ r....

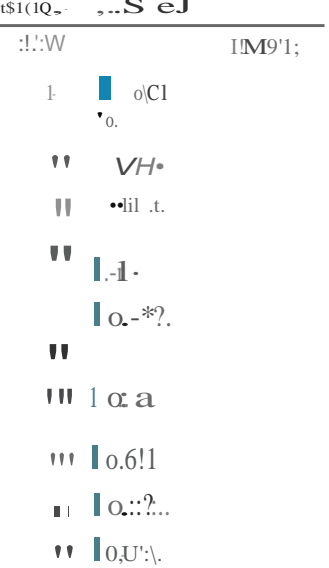

